\title{
A Dinâmica Produtiva Recente da Metrópole Paulista: Das Perspectivas Pós-Industriais à Consolidação do Espaço Industrial de Serviços*
}

\author{
Rogério dos Santos Acca
}

\section{INTRODUÇÃO}

$\mathrm{D}$ esde meados dos anos 1980, um crescente debate sobre o caráter industrial das metrópoles, em geral, e da Região Metropolitana de São Paulo - RMSP, em particular, tem sido trazido a lume pela literatura nacional e internacional.

Presente com mais força em um amplo conjunto de trabalhos que tratam da regionalização da economia brasileira, podemos situar uma linha de pesquisa que enxerga nas deseconomias de aglomeração plasmadas pelos elevados custos dos fatores de produção na metrópole, bem como pelo esgarçamento infra-estrutural de sua área, movimentos de sucessão regional da indústria no Estado de São Paulo. Sob essa perspectiva, territórios alternativos de industrialização estariam emergindo, em substituição à RMSP, como centros dinâmicos da indústria brasileira. O espaço da metrópole paulista não seria mais o espaço da indústria, uma vez que as (novas) economias de aglomeração do interior paulista e de outras regiões brasileiras dela retirariam sua

\footnotetext{
*Agradeço, em especial, a Glauco Arbix, por ter me aberto as portas do mundo, e a Bill Goldsmith, fonte profícua de generosidade e excelência acadêmica. Gostaria também de agradecer o a poio financeiro recebido da Fundação de Amparo à Pesquisa do Estado de São Paulo - FAPESP, sem o qual a realização desta pesquisa não seria possível. Por fim, sou grato ao parecerista anônimo de Dados pelos valiosos comentários a este texto.
}

DADOS - Revista de Ciências Sociais, Rio de Janeiro, Vol. 49, n-1, 2006, pp. 119 a 157. 
centralidade em termos da dinâmica da indústria nacional, em uma suposta reversão da polarização industrial - a qual, além dos fatores mencionados anteriormente, foi acentuada pelas políticas de desconcentração regional da atividade econômica promovidas pelo Estado brasileiro desde meados da década de 1970 (cf. Negri e Pacheco, 1994; Negri, 1996; Pacheco, 1999; Tavares, 2000; Caiado, 2002).

Simultaneamente a esse debate, podemos localizar uma outra tradição de pesquisa sobre o papel produtivo dos grandes conglomerados urbanos - esta é tratada mais intensamente pela literatura internacional e relativamente explorada na imprensa brasileira. Nesta tradição, ainda que sob pressupostos metodológicos distintos da abordagem anterior, também somos levados a concluir que o lugar da metrópole não é mais o da indústria manufatureira. A intensificação da globalização, a emergência de sociedades opulentas, as transações financeiras internacionais e os investimentos diretos estrangeiros agiriam como elementos condutores de uma mutação das megacidades em centros de serviços tradicionais e modernos, em substituição aos setores industriais como motores do dinamismo econômico regional (Cohen, 1981; Friedmann e Wolff, 1982; Feagin e Smith, 1987; Sassen, 1998; 2001; Short, 1996).

Por entender que essas duas estratégias de investigação, embora por caminhos teórico-metodológicos distintos, conduzem a interpretações equivocadas sobre o papel que a indústria ainda desempenha nos processos de mudança que a RMSP vem atravessando nos últimos anos, julgo relevante, neste artigo, tratar da persistência dos setores industriais como motores do desenvolvimento no território metropolitano paulista. Em poucas palavras, buscarei enfatizar que as transformações socioeconômicas da metrópole não se dão contra ou a favor da indústria, mas basicamente por causa dela.

Sempre tendo a literatura acima como referência, estruturei a pesquisa em três eixos básicos de análise teórica e empírica, os quais explorarei doravante.

Em primeiro lugar, um de meus objetivos principais será aprofundar o diálogo com a literatura em voga internacionalmente acerca das novas configurações dos espaços urbanos. Segundo essa literatura, uma nova era baseada nos fluxos globais de capital e informação transformaria o papel produtivo das metrópoles, conduzindo-as, inexoravelmente, a uma etapa histórica pós-industrial na qual as velhas engrenagens das manufaturas abandonariam os espaços urbanos para dar lu- 
gar ao setor de serviços modernos como o agente causal básico dos processos de desenvolvimento territorial. Nessa visão analítica, os setores industriais são deslocados para um papel coadjuvante no que concerne às novas configurações produtivas que tomam forma nas grandes metrópoles mundiais (cf. Short, 1996; Beaverstock et alii, 1999; Sassen, 1998; 2001; Taylor et alii, 2002).

Com base em uma orientação teórica e empírica alternativa, combaterei a idéia de que o caráter global das metrópoles seria capaz de agir, de modo ubíquo, como força motriz do desenvolvimento socioeconômico metropolitano. No caso da RMSP e seu entorno imediato, é possível verificar que as conexões causais entre os crescentes movimentos de globalização da economia e a desindustrialização metropolitana - impulsionada pela expansão do setor terciário moderno voltado para as atividades de controle corporativo - não podem ser empiricamente comprovadas no espaço urbano paulista (Acca, 2003).

Com efeito, a constatação empírica de que a indústria se constitui no motor do desenvolvimento territorial no Estado de São Paulo não anula o fato de que o setor de serviços avançados e o setor financeiro encontram na metrópole espaços privilegiados de localização, visto que na RMSP estão instaladas as sedes das principais multinacionais implantadas no Brasil e dos mais importantes bancos nacionais e estrangeiros. Dessa forma, sob meu enfoque de análise, os recentes movimentos de liberalização dos mercados financeiros internacionais e de desregulamentação do setor financeiro nacional apenas reforçam o papel da metrópole paulista como ponto de ancoragem dos capitais estrangeiros que atracam no Brasil.

Diante disso, as configurações produtivas da RMSP baseiam-se em um tipo de arranjo híbrido no espaço socioeconômico metropolitano, já que a consolidação do setor de serviços avançados e dos circuitos de acumulação do capital financeiro não é capaz de promover uma sucessão setorial na metrópole, com a qual o segmento manufatureiro entraria em inevitável declínio como motor do desenvolvimento territorial. Isto porque, tendo em vista o baixo grau de internacionalização da economia brasileira (Unctad, 2002a; 2002b), os setores apontados por vários pesquisadores como os novos dínamos da economia urbana - quais sejam, os serviços modernos e as movimentações financeiras globais apresentam, evidentemente, um desempenho pífio quando comparados com os centros financeiros internacionais, como Nova York e Lon- 
dres. Assim, o caráter global da metrópole paulista - e seu conseqüente aparato terciário avançado - parece estar longe de se transformar no carro-chefe da economia regional, como muitos pesquisadores observam (cf. Beaverstock et alii, 1999; Marques e Torres, 2000; Sassen, 1998; 2001; Tavares, 2000; Taylor et alii, 2002).

Em segundo lugar, tentarei recolocar o debate sobre o suposto esvaziamento industrial da metrópole - exposto em uma tradição de pesquisa bastante avançada nacionalmente, que toma as trajetórias declinantes do Valor de Transformação Industrial e do emprego industrial metropolitano como sinais indeléveis de seu declínio na estrutura produtiva paulista, em favor de espaços de produção no interior do Estado de São Paulo (ver, p.ex., Negri e Pacheco, 1994; Negri, 1996; Pacheco, 1999; Tavares, 2000; Caiado, 2002).

A partir de um esquema analítico alternativo, baseado em uma série de arranjos empíricos sobre os padrões de expansão territorial da indústria paulista, meu objetivo é demonstrar que o restrito processo de espraiamento da indústria em São Paulo para regiões contíguas à metrópole evidencia o peso da RMSP nos encadeamentos industriais do estado, de modo que as relações de proximidade espacial continuam a exercer forte influência sobre os movimentos locacionais do setor industrial estadual. Desse modo, buscarei avançar em relação às estratégias de investigação que separam a RMSP do restante do estado - construindo uma grande categoria denominada "interior" -, as quais apenas superestimam as perdas industriais da metrópole em favor de outras regiões (Negri e Pacheco, 1994; Negri, 1996; Pacheco, 1999; Tavares, 2000; Caiado, 2002).

Em terceiro lugar, será meu escopo ressaltar, com base nos dados disponíveis do Valor Adicionado Fiscal - VAF e do Valor de Transformação Industrial - VTI, o surgimento de novas economias de aglomeração metropolitanas estruturadas em torno da integração produtiva entre os setores secundário e terciário (Veltz, 1997; 2002; Miles e Boden, 2000; Pollard e Storper, 1996; Storper, 2000; Tomlinson, 2001).

As evidências disponíveis em termos empíricos nos encaminham para um tipo de análise alternativa que, ao invés de colocar o crescimento dos serviços em contraposição às atividades produtivas industriais, enfatiza que este crescimento se dá, em boa medida, em razão das imbricações organizacionais e produtivas existentes entre os segmentos industriais e de serviços - reforçando, assim, um hibridismo socioeco- 
nômico que tem sido, há muitos anos, uma das marcas distintivas da metrópole paulista, bem como de outras formações megaurbanas em países em desenvolvimento. Em outros termos, ressaltarei, em contraposição às vozes dominantes, a vocação industrial da RMSP, de sorte a combater a idéia da terciarização metropolitana.

\section{TRANSFORMAÇÕES PRODUTIVAS RECENTES NA METRÓPOLE PAULISTA: A PERSISTÊNCIA DA INDÚSTRIA COMO MOTOR DO DESENVOLVIMENTO TERRITORIAL}

As transformações recentes sofridas pela economia metropolitana estão longe de ser adequadamente compreendidas. O entendimento equivocado de que o espaço produtivo metropolitano estaria seguindo uma senda sem retorno rumo a uma economia terciária evidencia que as relações entre os setores industriais e de serviços são analisadas de modo estanque pela literatura, de maneira a engendrar confusões empíricas que têm conduzido a uma fantasia pós-industrial que se distancia cada vez mais da complexa dinâmica produtiva e territorial. Dinâmica que, por sua vez, está no centro de um movimento de reespacialização das atividades econômicas na malha produtiva metropolitana.

A "ilusão estatística" - para a qual somos freqüentemente conduzidos - de que o segmento terciário tenderia a dominar a paisagem socioeconômica metropolitana tem suas raízes em uma compreensão inadequada das relações que movem o setor industrial e o setor de serviços, as quais são caracterizadas, essencialmente, por novos padrões de organização da indústria, que vem experimentando processos intensos de reestruturação produtiva nos últimos anos. Assim, muitas atividades que durante o auge da produção em massa eram executadas no interior da empresa industrial foram externalizadas e atualmente são registradas como atividades do terciário, ainda que mantendo uma relação de simbiose com os processos de produção industrial. Dessa forma, o crescimento do setor terciário traz a lume a sua complementaridade com o setor industrial na organização socioeconômica do território, tornando a RMSP não um espaço metropolitano pós-industrial ou terciário, mas uma metrópole industrial de serviços, na medida em que não se trata de uma ruptura entre indústria e serviços ou de uma transição rumo aos serviços, mas de arranjos produtivos baseados na complementaridade entre esses dois setores da vida econômica (Moulaert et alii, 1997; Miles e Boden, 2000; Tomlinson, 2001; Veltz, 2002), e cujas expressões territoriais se distanciam daquelas trazidas à baila pelos 
teóricos da pós-industrialização (Sassen, 1998; 2001; Taylor et alii, 2002).

Diante da emergência de arranjos territoriais cada vez mais marcados pela interdependência entre os setores econômicos, entendo que poucos autores têm se debruçado sobre a relação entre os movimentos de aglomeração industrial em áreas metropolitanas - e as regiões em seu entorno - e a formação, cada vez mais intensa, de encadeamentos intersetoriais. $\mathrm{O}$ foco exclusivo no setor industrial ou no segmento de serviços turva as perspectivas que se abrem a novas possibilidades de configuração territorial que exorbitam as fronteiras entre os municípios da RMSP e outras regiões do Estado de São Paulo. Nesse sentido, o setor de serviços, muito longe de representar um deslocamento do setor industrial como fonte de riqueza e desenvolvimento, age como um determinante locacional basilar na construção de uma nova economia industrial - altamente dependente do setor de serviços -, o que faz da metrópole fator essencial nesse novo esquema de organização socioespacial (Veltz, 2002).

A expressão locacional dessa dependência pode ser verificada no Estado de São Paulo, onde as crescentes deseconomias de aglomeração metropolitanas não produziram nem desindustrialização, tampouco uma dispersão territorial consistente das firmas industriais, ainda que observemos a expansão da infra-estrutura de transporte estadual e o advento da "guerra fiscal" em meados dos anos 1990.

É importante, dessa forma, explorar algumas características distintivas dos serviços e sua organização produtiva para que possamos entender as interações intersetoriais que estão na base de várias aglomerações produtivas metropolitanas, as quais tendem a funcionar como amortecedores de processos mais amplos de desconcentração regional da atividade produtiva. Em primeiro lugar, a produção de serviços envolve uma grande quantidade de trabalho intelectual que produz uma série de bens intangíveis e específicos para uma gama diferenciada de clientes. Em segundo lugar, esse caráter customizado dos serviços modernos envolve a interação freqüente entre produtores e clientes. Nas palavras de Miles e Boden (2000:8), "os serviços são 'cliente-intensivos', os quais requerem insumos do consumidor no processo de concepção/produção". Como conseqüência desses dois fatores, a produção de serviços envolve, por um lado, baixas economias de escala uma vez que sua produção não é uniforme, porque determinada pelas 
necessidades específicas do consumidor final - e, por outro lado, uma constante necessidade de proximidade com o cliente, a qual torna a aglomeração quase inevitável, mesmo com a evolução dos mecanismos de transmissão de dados e dos meios físicos de transporte (Moulaert et alii, 1997; Miles e Boden, 2000).

A concentração das atividades intensivas em conhecimento na metrópole está baseada, destarte, em externalidades imateriais que se tornam componentes basilares na geração e reprodução de conhecimento e inovação, tanto na indústria como nos serviços. Em outros termos, a descontinuidade, a produção em baixa escala e a necessidade constante de interações intra e intersetoriais tornam essas externalidades componentes essenciais da atratividade econômica metropolitana para os setores mais modernos da economia. Com efeito, essas interações intersetoriais trazem à baila novas reflexões sobre o papel das políticas públicas que visem a estimular a produção industrial, já que o foco exclusivo nas manufaturas pode turvar ou mesmo enfraquecer os efeitos positivos das relações sociais que exorbitam tanto as fronteiras entre os setores econômicos como os limites territoriais formais estabelecidos nos mapas.

O crescimento do setor de serviços, desse modo, é indissociável da dinâmica industrial, reforçando a construção de um caráter socioeconômico híbrido na metrópole paulista, uma vez que os serviços se desenvolvem em um movimento estritamente dependente das relações de produção plasmadas no interior da indústria. Posto de outra forma, o avanço do terciário ocorre, em boa medida, como resultado de processos de reordenação produtiva na indústria, não trilhando um caminho paralelo ou contrário aos mecanismos da produção manufatureira. É importante enfatizar, assim, que os processos de reorganização das relações de produção no núcleo-base da economia paulista - entre os quais a consolidação de um setor terciário moderno metropolitano estão fortemente relacionados às intensas transformações experimentadas pelo setor industrial nos anos 1990.

Os diferenciais de produtividade entre as atividades industriais e de serviços podem nos conduzir a uma falsa impressão de que estamos vivenciando um inevitável declínio do setor industrial como setor-chave do desenvolvimento econômico. Nesse sentido, as maiores taxas de produtividade no setor industrial em comparação com os serviços contribuem não somente para uma participação mais robusta desse setor 
na composição do valor adicionado ou do Produto Interno Bruto - PIB, mas também para um declínio da contribuição do segmento industrial na produção de valor adicionado e, conseqüentemente, do PIB. Ademais, o aprofundamento das estratégias de reestruturação produtiva neste segmento promove, inter alia, uma elevação considerável da produtividade, afetando negativamente a base quantitativa do emprego industrial. Não por acaso, alguns autores acertadamente alertam que a dinâmica do emprego deve ser analisada com prudência quando se trata de apurar a emergência e a consolidação de uma economia de serviços ou de metrópoles terciárias (Veltz, 2002; Comin e Amitrano, 2003).

Nessa medida, a inevitabilidade da desindustrialização ou terciarização da metrópole paulista, bem como sua transfiguração socioeconômica impulsionada pelos serviços modernos, devem ser tratadas com cautela, sob pena de caracterizações imprecisas da estrutura produtiva metropolitana. Diante disso, somos levados a concluir que tomar o declínio do emprego manufatureiro como sinal da decadência estrutural da indústria no território enseja um erro metodológico que obscurece a compreensão adequada da dinâmica socioeconômica da RMSP. Se é certo afirmar que o setor industrial apresenta níveis mais elevados de produtividade em relação aos serviços, é também correto asseverar que a indústria se move em torno de uma capacidade maior de poupar postos de trabalho (Chang, 1996:57).

Como conseqüência direta das questões levantadas até este ponto, não posso me esquivar de trazer à baila questões relacionadas às mudanças no quadro de regulação macroeconômica levadas a cabo a partir do início dos anos 1990, marcadas pela implementação de uma agenda de governo perpassada por estratégias de abertura comercial e desregulamentação dos mercados nacionais, a qual provocou impactos profundos sobre a principal base produtiva do país, qual seja, a RMSP. As agressivas medidas de redução das barreiras tarifárias e não-tarifárias que tomaram forma logo no início da década de 1990, associadas à política de valorização cambial pós-Real, produziram sensíveis transformações no ambiente regulatório ao qual se submetia o setor produtivo desde os anos desenvolvimentistas, marcados por forte intervenção estatal e graus elevados de proteção aos setores industriais (Hay, 1997).

As conseqüências dessas medidas para o setor produtivo nacional e, mais especificamente, para a indústria metropolitana paulista - que, 
devido ao seu caráter multiespecializado e à complexidade de suas cadeias produtivas em vários segmentos industriais, se tornou mais sensível à mudança brusca da dinâmica macroeconômica - foram profundas, no sentido de que forçaram intensos movimentos defensivos de reestruturação produtiva ${ }^{1}$ em vários setores da indústria, para fazer face a um novo patamar de competitividade estabelecido por um sistema de preços definido, em larga medida, por variáveis exógenas advindas da dinâmica do mercado internacional e do câmbio. Acerca da transformação profunda e rápida dos mecanismos de regulação da economia brasileira, Carneiro (2002:317) observa que a mudança mais importante "[...] é a diminuição das relações intersetoriais da economia brasileira. Na sua operação corrente e, mais ainda, na sua reprodução, as articulações entre os vários setores produtivos foram reduzidas. Ou seja, o padrão de crescimento fundado no adensamento das relações interdepartamentais foi desarticulado".

Com efeito, inúmeros setores da cadeia produtiva ficaram desprotegidos, passíveis de sucumbir à competição internacional estimulada por uma política macroeconômica que favorecia um elevado grau de internacionalização dos bens produzidos nacionalmente por meio de importações. Além disso, os novos patamares de regulação erigidos pelo governo brasileiro contribuíram para desagregar setores que não apresentavam as mínimas condições de enfrentar a concorrência em um ambiente econômico fortemente liberalizado - como mostram os casos dos segmentos têxtil e de autopeças, cuja presença é marcante na RMSP. Nesse sentido, a relativa perda de dinamismo da indústria metropolitana, revelada pelo decréscimo da participação desse setor na composição do valor adicionado metropolitano e estadual, pode ser explicada, em considerável medida, pelas escolhas e pelos processos que dominaram a agenda de governo nos anos 1990, claramente orientada para a abertura comercial - que se revelou traumática para a indústria da RMSP, em comparação com outras regiões.

Com base nessas questões, a análise da dimensão macroeconômica que caracterizou os anos 1990 permite-nos algumas conclusões basilares no sentido de descartar algumas hipóteses equivocadas sobre a terciarização da metrópole e sobre a perda de dinamismo da indústria como motor do desenvolvimento na RMSP. Assim, três considerações são peremptórias no sentido de deslocar o foco da análise de uma suposta transição setorial para uma análise focada na integração indústriaserviços. 
Primeiro, os movimentos de abertura comercial tiveram um impacto profundo nos níveis de produtividade da indústria paulista, intensificando os diferenciais de produtividade entre os setores industrial e de serviços. Como corolário, a liberalização da economia posta em marcha nos anos 1990 promoveu um choque de preços relativos em favor do setor de serviços, o qual, por sua vez, passa a refletir-se na composição do valor adicionado (Comin e Amitrano, 2003).

Segundo, as estratégias neoliberais dos anos 1990 ensejaram um vertiginoso processo de reestruturação produtiva defensiva por parte do setor industrial, o qual se lastreou em intensos processos de terciarização que, por seu turno, resultaram na externalização de atividades antes desenvolvidas no interior das empresas. Dessa forma, a reestruturação produtiva da década de 1990, longe de plasmar uma transição setorial da metrópole em direção aos serviços, reforçou os laços de funcionalidade entre o secundário e o terciário mediante uma industrialização das atividades de serviços, gerando um grau crescente de interpenetração organizacional entre os dois setores, assim como uma forte integração espacial da produção no espaço metropolitano, a qual está na base da formação de um espaço industrial de serviços por natureza híbrido ${ }^{2}$. Portanto, o peso maior dos serviços na composição do valor adicionado deve ser visto com mais cuidado, já que a transferência de atividades industriais - no âmbito dos esquemas de industrialização dos serviços - para o setor terciário nos leva a concluir que parte do valor adicionado produzido por este setor é indissociável da produção manufatureira.

Terceiro, os padrões locacionais do novo ciclo de investimentos no setor de serviços, que irrompeu após a abertura e desregulamentação dos mercados nacionais e as privatizações, revelam o peso da malha produtiva da RMSP sobre as demais regiões do Estado de São Paulo, uma vez que a metrópole paulista absorve parcelas crescentes do investimento nos serviços diretamente relacionados à produção industrial. Contrariamente às hipóteses da metrópole terciária, é mister observar a emergência - impulsionada pela intensa reestruturação produtiva na indústria - de economias de aglomeração derivadas da integração espacial e organizacional entre o secundário e o terciário, a qual reforça o espaço industrial de serviços na metrópole paulista. Sob minha perspectiva de análise, os padrões de investimento e da produção de valor adicionado na RMSP mostram que o setor de serviços moderno que nela se configura só pode existir porque lá está instalado o mai- 
or e mais complexo parque produtivo nacional. À guisa de ilustrar esse movimento, pode-se citar o boom, nas cidades de São Paulo e do Méxi$\mathrm{co}$, dos setores industriais intensivos em conhecimento, os quais apresentam as mais intensas sinergias com o setor de serviços (Bessa, 2003; Aguilar, 2002).

Isto posto, julgo relevante destacar que uma análise que não leve em conta a complexa relação funcional entre os serviços e os ambientes de produção industrial torna-se inócua na explicação das configurações produtivas da RMSP - desta forma, a industrialização dos serviços, no sentido de que uma gama variada de insumos intelectuais da produção industrial tem sido engendrada a partir de relações sociais que exorbitam os muros da fábrica, transmutando-se, estatisticamente, em atividades de serviços. Posto de outra forma, a economia vem se organizando, de maneira cada vez mais intensa, em torno de mecanismos de industrialização dos serviços, gerando novas e variadas configurações na divisão do trabalho entre os agentes econômicos. A complementaridade entre esses dois setores, que ganha corpo com novos paradigmas de reestruturação produtiva da indústria, pode ser evidenciada pelo fato de que boa parte dos serviços de alto valor agregado - como os serviços de consultoria jurídica; contabilidade e auditoria; gestão empresarial; propaganda, publicidade e marketing; atividades de informática; pesquisa e desenvolvimento (P\&D) - está diretamente relacionada ao setor manufatureiro da economia, tanto em termos organizacionais como em termos espaciais (Pollard e Storper, 1996:2).

Neste ponto, algumas ressalvas são necessárias. Primeiro, a de que as diferentes configurações espaciais e produtivas assumidas pelas atividades de serviços não nos permitem incorrer em generalizações pobres sobre as estruturas socioeconômicas das metrópoles, na medida em que o contato geográfico e organizacional entre os setores industrial e de serviços é apenas um de uma miríade de esquemas de regulação da produção no território. Desse modo, podemos identificar espaços produtivos nos quais realmente existe um descolamento entre esses dois setores, principalmente no que concerne às metrópoles que se organizam em torno da exportação de serviços, como Nova Iorque. Nesta cidade, diferentemente de São Paulo, as atividades de serviços não estão fortemente integradas espacialmente com as empresas industriais - tomando como referência a perda estrutural de dinamismo da indústria na região metropolitana organizada ao redor de Nova York (Markusen, 1999). 
A segunda ressalva visa a evitar uma generalização imprópria a respeito do setor de serviços, pois a afirmação de que esse setor cresce na esteira da indústria não significa dizer que todos os serviços são dependentes da produção industrial em termos de sua configuração, tomando em linha de conta que o modus operandi do universo econômico é composto por muitas atividades as quais nem mesmo de maneira indireta fornecem insumos para a indústria (Pollard e Storper, 1996). Se as fronteiras entre as atividades industriais e de serviços são tênues e difíceis de serem determinadas com acurácia, como observa Veltz (1997), isso não significa que elas não existam.

Doravante, orientarei minha análise dos recentes padrões empíricos metropolitanos a partir dos eixos de argumentação expostos até aqui.

Se se verifica, de fato, um processo de fragmentação territorial da produção no Estado de São Paulo à medida que avança a produção industrial em outras regiões do estado, às expensas da RMSP, não podemos dizer que esse processo seja independente da estrutura produtiva metropolitana, nem asseverar que essa desconcentração relativa da produção se faça sob os auspícios de um deslocamento da vocação industrial metropolitana rumo ao terciário moderno. A configuração de uma região metropolitana expandida denota, portanto, uma reorganização das economias de aglomeração no território - em razão das deseconomias de aglomeração que surgiram no núcleo metropolitano, motivando uma dispersão limitada da indústria - e uma densa integração organizacional e territorial das indústrias com os provedores de serviços que adotaram estratégias locacionais predominantemente fundadas nas economias de urbanização fornecidas pela RMSP e, mais especificamente, pelo município de São Paulo (Bessa, 2003).

\section{PADRÕES EMPÍRICOS NA METRÓPOLE PAULISTA: TENDÊNCIAS RECENTES DO VALOR ADICIONADO FISCAL}

De acordo com as premissas teóricas e empíricas que orientam este artigo, buscarei, nesta seção, ilustrar a persistência da natureza industrial da metrópole paulista. Para tanto, concentrar-me-ei nos indicadores fornecidos pelo VAF do Estado de São Paulo. Assim, seremos capazes de perceber que as transformações sofridas pela estrutura produtiva metropolitana estão fundamentalmente relacionadas às modificações orgânicas experimentadas pela empresa industrial como resposta 
às pressões competitivas derivadas da transição institucional operada na economia brasileira na década de 1990.

Ao considerarmos a trajetória da composição setorial do VAF da RMSP desde 1995 (ver Gráfico 1), poderemos perceber que os movimentos da metrópole rumo à configuração de uma economia de serviços estão longe de serem consumados. Os dados empíricos disponíveis não nos permitem afirmar que as transformações sofridas em tempos recentes pela metrópole paulista desembocarão em uma metrópole predominantemente de serviços.

Corroborando a minha hipótese de que a indústria não perdeu seu papel estrutural de motor do desenvolvimento territorial - e de que tampouco existe uma tendência clara para isso -, os dados do Gráfico 1 mostram que o segmento industrial metropolitano reina absoluto na produção do VAF gerado na RMSP. Destarte, o crescimento do setor de serviços não pode ser dissociado da dinâmica industrial na metrópole paulista, uma vez que, como principal região industrial do país, sofreu mais intensamente os efeitos da abertura econômica e da conseqüente mudança dos padrões competitivos, aos quais teve de se adaptar rapidamente. Em consonância com o apontado anteriormente, o pequeno declínio da indústria no VAF tem muito menos a ver com uma transição setorial terciária do que com os movimentos de reestruturação produtiva das empresas industriais, os quais agiram como fatores causais essenciais na construção de uma economia industrial de serviços na qual as fronteiras entre o secundário e o terciário se tornam fluidas. Desta forma, se uma larga camada dos serviços cresce em função da produção industrial, podemos dizer, com efeito, que houve uma migração de valor da indústria para os serviços - pois a indústria responde, em termos organizacionais, pela geração desse valor.

O choque de preços relativos em favor dos serviços, como evidenciam Comin e Amitrano (2003), foi um fator fundamental para o crescimento desse setor na composição do VAF da RMSP a partir da década de 1990. Certamente, uma parte desse crescimento é resultado de diferenciais de produtividade - que se intensificaram com a abertura da economia brasileira na década de 1990 - entre a indústria e os serviços, os quais provocam uma mudança na relação de preços entre os dois setores em favor deste último segmento.

No que tange ao município de São Paulo (ver Gráfico 2), o contexto econômico de abertura comercial, desregulamentação dos mercados fi- 


\section{Gráfico 1}

Composição Setorial do Valor Adicionado Fiscal na Região Metropolitana de São Paulo (1995-2000), em Porcentagem

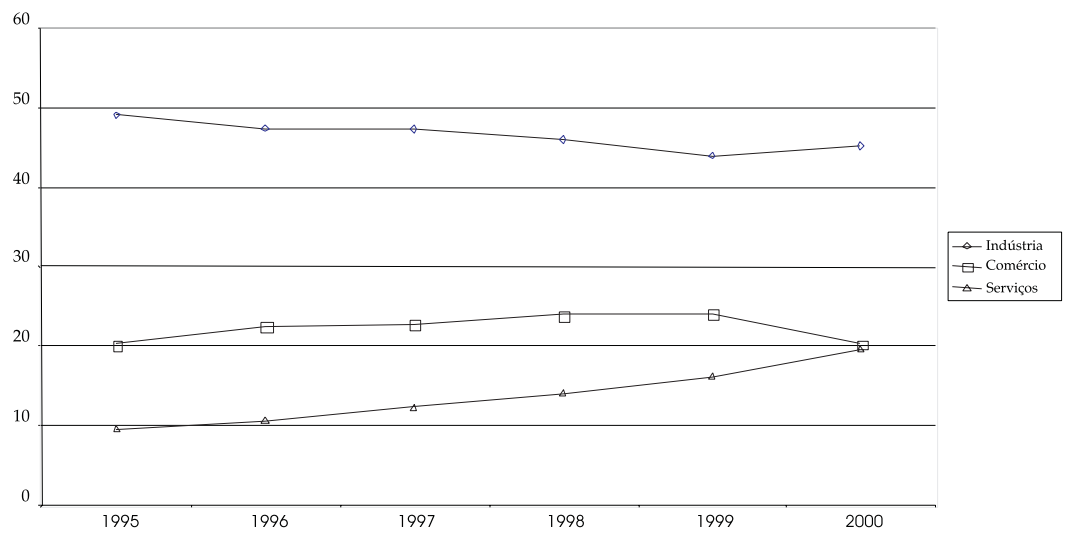

Fonte: Fundação Seade (1996) (dados da Secretaria da Fazenda do Estado de São Paulo). Elaboração do autor.

nanceiros nacionais, redução tarifária, estabilização monetária baseada em altas taxas de juros e privatizações produziu um efeito mais profundo, tendo em vista a maior sensibilidade do município às mudanças de ordem macroeconômica, uma vez que a cidade conta com uma extensa base produtiva nos setores industrial e de serviços. Decerto, os graus de concentração das atividades econômicas mais complexas no município de São Paulo o converteram no epicentro das transformações produtivas metropolitanas e nacionais que marcaram a década de 1990.

A composição setorial do VAF do município de São Paulo apresenta uma alteração significativa no período que se estende de 1993 a 2000, demonstrando um acentuado declínio da participação relativa da indústria na sua geração. A indústria continua sendo a principal fonte de geração do VAF municipal, ainda que a tendência a curto prazo seja a superação do segmento industrial pelo de serviços na composição setorial do VAF paulistano. A despeito disso, as transformações que ocorrem na zona nuclear da metrópole paulista não podem ser descoladas da dinâmica produtiva industrial, uma vez que a cidade de São Paulo vem se configurando como um complexo centro de serviços produtivos, os quais apresentam uma forte dependência da indústria tanto em termos territoriais como em termos organizacionais - em um pa- 
A Dinâmica Produtiva Recente da Metrópole Paulista...

Gráfico 2

Composição Setorial do Valor Adicionado Fiscal na Região Metropolitana de São Paulo (1995-2000), em Porcentagem

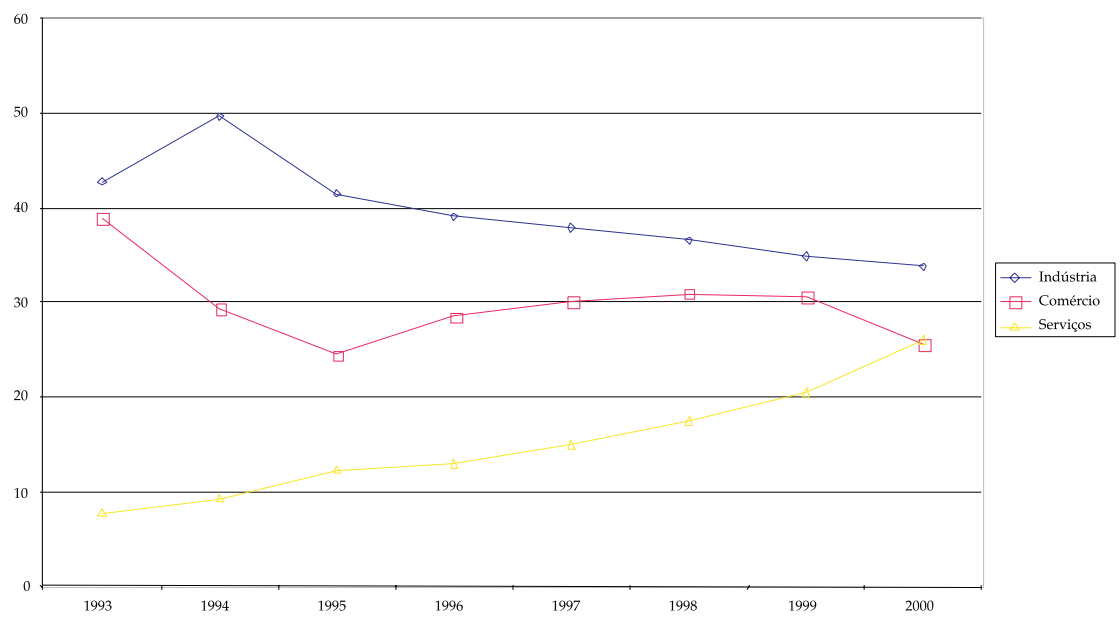

Fonte: Fundação Seade (1996) (dados da Secretaria da Fazenda do Estado de São Paulo). Elaboração do autor.

drão produtivo territorial muito diferente daquele verificado nas cidades globais, onde os serviços voltados às movimentações financeiras internacionais e ao controle corporativo das empresas transnacionais ofuscam a indústria dessas regiões como motores das transformações econômicas recentes (Markusen, 1999b).

Nesse sentido, os padrões empíricos verificados no município de São Paulo são aqueles que mais se aproximam de um esquema híbrido de organização produtiva - ou seja, baseado em uma complexa integração secundário-terciário e no qual a dinâmica do setor financeiro não promove uma substituição do setor industrial como elemento dinâmico da economia territorial.

Entre 1993 e 2001, podemos verificar na RMSP um padrão de expansão da produção industrial para fora dos centros industriais tradicionais da metrópole - como a própria capital e a região do $A B C$-, uma vez que as maiores taxas de crescimento do valor adicionado da indústria se encontram nos municípios não pertencentes ao eixo produtivo capital-ABC: o município de Guarulhos, que entre 1993 e 2000 eleva de 9,4\% para 10,6\% sua participação no bolo do VAF da RMSP, e os demais 
Tabela 1

Distribuição do Valor Adicionado Fiscal, segundo Setores de Atividade e Sub-Regiões da RMSP (1993-2000), em Porcentagem

\begin{tabular}{l|r|r|r|r|r|r|r|r}
\hline \multirow{2}{*}{$\begin{array}{l}\text { Setores de Atividade } \\
\text { Sub-Regiões }\end{array}$} & \multicolumn{7}{|c}{ Distribuição do Valor Adicionado Fiscal } \\
\cline { 2 - 8 } & $\mathbf{1 9 9 3}$ & $\mathbf{1 9 9 4}$ & $\mathbf{1 9 9 5}$ & $\mathbf{1 9 9 6}$ & $\mathbf{1 9 9 7}$ & $\mathbf{1 9 9 8}$ & $\mathbf{1 9 9 9}$ & $\mathbf{2 0 0 0}$ \\
\hline Indústria & & & & & & & & \\
Capital & 45,0 & 42,2 & 42,3 & 44,1 & 41,6 & 41,9 & 40,6 & 38,8 \\
ABC & 27,6 & 32,1 & 31,4 & 29,0 & 31,3 & 29,1 & 28,2 & 28,0 \\
Guarulhos & 9,4 & 8,5 & 9,5 & 9,9 & 9,8 & 9,4 & 10,0 & 10,6 \\
Demais municípios & 18,0 & 17,2 & 16,8 & 17,0 & 17,4 & 19,5 & 21,2 & 22,6 \\
Total Indústria & $\mathbf{1 0 0 , 0}$ & $\mathbf{1 0 0 , 0}$ & $\mathbf{1 0 0 , 0}$ & $\mathbf{1 0 0 , 0}$ & $\mathbf{1 0 0 , 0}$ & $\mathbf{1 0 0 , 0}$ & $\mathbf{1 0 0 , 0}$ & $\mathbf{1 0 0 , 0}$ \\
Serviços & & & & & & & & \\
Capital & 63,1 & 47,4 & 70,1 & 68,8 & 65,0 & 65,4 & 64,9 & 68,9 \\
ABC & 15,0 & 30,8 & 12,8 & 12,1 & 13,4 & 13,1 & 12,4 & 11,8 \\
Guarulhos & 9,3 & 8,6 & 7,5 & 7,7 & 9,2 & 8,5 & 8,5 & 7,0 \\
Demais municípios & 12,6 & 13,3 & 9,6 & 11,4 & 12,4 & 13,0 & 14,2 & 12,3 \\
Total Serviços & $\mathbf{1 0 0 , 0}$ & $\mathbf{1 0 0 , 0}$ & $\mathbf{1 0 0 , 0}$ & $\mathbf{1 0 0 , 0}$ & $\mathbf{1 0 0 , 0}$ & $\mathbf{1 0 0 , 0}$ & $\mathbf{1 0 0 , 0}$ & $\mathbf{1 0 0 , 0}$ \\
Comércio & & & & & & & & \\
Capital & 80,6 & 64,4 & 60,9 & 67,9 & 69,9 & 68,5 & 65,3 & 65,8 \\
ABC & 7,2 & 12,0 & 13,0 & 8,8 & 7,5 & 9,7 & 9,9 & 9,3 \\
Guarulhos & 4,4 & 9,6 & 7,2 & 6,8 & 6,8 & 6,6 & 7,6 & 7,7 \\
Demais municípios & 7,8 & 14,0 & 17,3 & 16,0 & 15,8 & 15,2 & 17,2 & 17,2 \\
Total Comércio & $\mathbf{1 0 0 , 0}$ & $\mathbf{1 0 0 , 0}$ & $\mathbf{1 0 0 , 0}$ & $\mathbf{1 0 0 , 0}$ & $\mathbf{1 0 0 , 0}$ & $\mathbf{1 0 0 , 0}$ & $\mathbf{1 0 0 , 0}$ & $\mathbf{1 0 0 , 0}$ \\
\hline
\end{tabular}

Fontes: Secretaria da Fazenda do Estado de São Paulo (dados do VAF) e Fundação Seade (1996). Para os anos de 1993 a 1999, baseamo-nos nos dados fornecidos por Comin e Amitrano (2003:64).

municípios da RMSP (excetuando-se o complexo São Paulo-ABC-Guarulhos), que de 18,0\%, em 1993, passam a contribuir com 22,6\% do VAF da indústria da RMSP em 2000, um ganho relativo de 25,5\% em oito anos (ver Tabela 1).

Os municípios do $\mathrm{ABC}$, a despeito do intenso processo de reestruturação produtiva levado a cabo pelas empresas da região, como resposta às pressões competitivas derivadas do contexto macroeconômico dos anos 1990, mantêm praticamente inalterada a sua participação na geração do VAF da RMSP (27,6\% em 1993 e 28\% em 2001). Assim, longe de confirmar as previsões funestas acerca do futuro da indústria no $\mathrm{ABC}$, os dados do VAF confirmam uma vocação marcante dos municípios da região para a alocação de atividades industriais.

Especificamente no que toca ao município de São Paulo, notamos um padrão de desconcentração de seu parque produtivo para outras re- 
giões do estado, ainda que isso não caracterize uma redefinição de suas funções econômicas, ao modo das cidades globais ou mundiais. O caráter industrial do município pode ser evidenciado pela elevada participação de sua base produtiva na composição do VAF da indústria metropolitana $-38,8 \%$ em 2000. Não obstante o município tenha sofrido as maiores perdas relativas de participação no valor adicionado da indústria - perdeu 6,2 pontos percentuais de sua contribuição entre 1993 e 2000 -, vale ressaltar que esse processo tem uma forte relação com a fragmentação da produção na metrópole - com a expansão da malha produtiva metropolitana para regiões contíguas à capital e à RMSP - e com a tendência da consolidação de um fenômeno metropolitano que abarca as regiões no entorno da metrópole paulista, redefinindo-a (Lencioni, 2003a; 2003b).

Do ângulo da indústria, podemos observar um processo de dispersão limitada em termos territoriais que coincide com a consolidação de um espaço produtivo no entorno da RMSP que não ultrapassa um raio de 150 km do núcleo metropolitano (Azzoni, 1986; Storper, 1991; Matteo e Tapia, 2002).

A primeira tendência dessa nova configuração produtiva no Estado de São Paulo é o reforço da centralidade do setor de serviços no núcleo metropolitano. Capitaneada pela cidade de São Paulo, que apresentou um crescimento acentuado de sua participação, já elevada, na produção do VAF dos serviços do Estado de São Paulo - de 28,5\% em 1993 para 41,3\% em 2000 -, a RMSP aumentou a sua participação na composição do valor adicionado dos serviços do estado em quase 10 pontos percentuais entre os anos de 1995 e 2000 - passando de 50,1\% para $60,0 \%$ (ver Tabela 2).

A segunda tendência diz respeito à perda de participação da RMSP na composição do valor adicionado fiscal da indústria estadual em benefício das regiões de Campinas, Santos, São José dos Campos e Sorocaba, demonstrando um movimento de dispersão-integração da malha produtiva metropolitana, fator fundamental na reorganização da metrópole em termos urbanos e produtivos.

Dispersão porque estamos diante de um avanço da industrialização para outras regiões do estado - ressaltando que as regiões contíguas à RMSP são as maiores absorvedoras do VAF da indústria anteriormente produzido no interior da metrópole tradicional, constituída sob o projeto desenvolvimentista nos anos 1950. 
Integração porque a dispersão do aparato industrial metropolitano não se faz sem a influência da RMSP como centro de gravidade da malha produtiva que se forma na esteira da expansão da metrópole, principalmente se tomarmos como referência a densidade das cadeias produtivas que dependem vitalmente de um setor de serviços intensivo em conhecimento do qual a RMSP é a principal provedora. Ademais, a RMSP continua sendo o principal centro industrial do país, ainda que tenha reduzido sua participação na estrutura produtiva estadual e nacional.

Tabela 2

Participação da RMSP no Valor Adicionado Fiscal do Estado de São Paulo, segundo Setores de Atividade (1995-2000), em Porcentagem

\begin{tabular}{l|c|c|c|c|c|c}
\hline \multirow{2}{*}{$\begin{array}{l}\text { Setores de } \\
\text { Atividade }\end{array}$} & \multicolumn{6}{|c}{ Distribuição do Valor Adicionado } \\
\cline { 2 - 7 } & $\mathbf{1 9 9 5}$ & $\mathbf{1 9 9 6}$ & $\mathbf{1 9 9 7}$ & $\mathbf{1 9 9 8}$ & $\mathbf{1 9 9 9}$ & $\mathbf{2 0 0 0}$ \\
\hline Indústria & 50,2 & 51,7 & 52,1 & 49,4 & 46,7 & 41,2 \\
Serviços & 50,1 & 50,7 & 51,3 & 53,2 & 55,2 & 60,0 \\
Comércio & $\mathbf{5 3 , 6}$ & $\mathbf{6 0 , 0}$ & $\mathbf{5 8 , 9}$ & $\mathbf{5 8 , 0}$ & $\mathbf{5 8 , 0}$ & $\mathbf{5 6 , 9}$ \\
Total RMSP & $\mathbf{5 1 , 0}$ & $\mathbf{5 3 , 7}$ & $\mathbf{5 3 , 7}$ & $\mathbf{5 2 , 3}$ & $\mathbf{5 1 , 1}$ & $\mathbf{4 7 , 8}$ \\
\hline
\end{tabular}

Fontes: Secretaria da Fazenda do Estado de São Paulo (dados do VAF) e Fundação Seade (1996). Elaboração do autor.

Se é certo que verificamos na RMSP um declínio relativo de sua participação no VAF estadual da indústria - de 50,2\% em 1995 para 41,2\% em 2000 -, devemos enfatizar que a porção da metrópole ainda se mantém elevada, mostrando seu forte caráter industrial (ver Tabela 2).

A consolidação da "metrópole expandida" pode ser comprovada com base nos dados do VAF do Estado de São Paulo no período compreendido entre os anos de 1995 e 2000. Ao tomarmos como referência de análise a "metrópole expandida", notamos que sua participação no VAF cresce nos segmentos industrial, comercial e de serviços (ver Tabela 3).

No caso do setor industrial, é interessante notar que, diferentemente do que verificamos em relação à RMSP, a contribuição da "metrópole expandida" para a composição do VAF desse setor no Estado de São Paulo praticamente se mantém inalterada no espaço temporal considerado. A participação da "metrópole expandida" no VAF da indústria 
estadual, que era de $88,5 \%$ em 1995, passa a $88,3 \%$ em 2000, demonstrando uma preponderância inquebrantável dessa região na produção industrial paulista. Além disso, a dependência espacial e organizacional em relação ao aparato produtivo localizado no núcleo metropolitano revela-se evidente, pois a RMSP tem perdido participação para regiões no seu entorno imediato (ver Tabelas 3 e 4). Com relação ao segmento de serviços, o crescimento da participação da "metrópole expandida" no VAF do Estado de São Paulo foi significativo - de 77,6\% em 1995 para 82,8\% em 2000 (ver Tabela 3).

Tabela 3

Participação da "Metrópole Expandida"* no Valor Adicionado Fiscal do Estado de São Paulo, segundo Setores de Atividade (1995-2000), em Porcentagem

\begin{tabular}{l|c|c|c|c|c|c}
\hline \multirow{2}{*}{ Setores de Atividade } & \multicolumn{5}{|c}{ Distribuição do Valor Adicionado } \\
\cline { 2 - 7 } & $\mathbf{1 9 9 5}$ & $\mathbf{1 9 9 6}$ & $\mathbf{1 9 9 7}$ & $\mathbf{1 9 9 8}$ & $\mathbf{1 9 9 9}$ & $\mathbf{2 0 0 0}$ \\
\hline Indústria & 88,5 & 87,5 & 88,2 & 87,4 & 86,7 & 88,3 \\
Serviços & 77,6 & 79,2 & 80,0 & 79,8 & 81,4 & 82,8 \\
Comércio & $\mathbf{8 2 , 9}$ & $\mathbf{8 3 , 6}$ & $\mathbf{8 3 , 2}$ & $\mathbf{8 3 , 7}$ & $\mathbf{8 3 , 9}$ & $\mathbf{8 3 , 9}$ \\
Total Metrópole Expandida & $\mathbf{8 5 , 8}$ & $\mathbf{8 5 , 4}$ & $\mathbf{8 5 , 7}$ & $\mathbf{8 5 , 2}$ & $\mathbf{8 5 , 0}$ & $\mathbf{8 6 , 4}$ \\
\hline
\end{tabular}

Fontes: Secretaria da Fazenda do Estado de São Paulo (dados do VAF) e Fundação Seade (1996). Elaboração do autor.

*Inclui Região Metropolitana de São Paulo, Região Metropolitana da Baixada Santista, Região Administrativa de São José dos Campos e Região Administrativa de Sorocaba.

O motor dinâmico da economia paulista, nesse sentido, não se constrói a partir de uma economia de serviços, mas sim de interações socioeconômicas no âmbito do território que apontam para uma economia industrial de serviços, na qual a integração intersetorial se faz essencial para o funcionamento da produção no espaço (Moulaert et alii, 1997; Miles e Boden, 2000; Veltz, 2002).

Nesse contexto, a capital paulista, mesmo perdendo participação no VAF da indústria e reordenando suas engrenagens socioeconômicas, faz da indústria seu modo de vida. Cabe observar que a indústria da capital foi responsável por 16,0\% do VAF gerado pela indústria no Estado de São Paulo em 2000, o que a colocou no segundo posto como região industrial e na primeira posição como município industrial - perdendo 
apenas para a Região Administrativa de Campinas, que produziu 23,6\% do VAF industrial estadual (ver Tabela 4).

Tabela 4

Participação das Sub-Regiões da "Metrópole Expandida" no Valor Adicionado Fiscal da Indústria do Estado de São Paulo (1995-2000), em Porcentagem

\begin{tabular}{l|r|r|r|r|r|r}
\hline \multirow{2}{*}{$\begin{array}{l}\text { Setor de Atividade } \\
\text { Sub-regiões }\end{array}$} & \multicolumn{5}{|c}{ Distribuição do Valor Adicionado } \\
\cline { 2 - 7 } Indústria & $\mathbf{1 9 9 5}$ & $\mathbf{1 9 9 6}$ & $\mathbf{1 9 9 7}$ & $\mathbf{1 9 9 8}$ & $\mathbf{1 9 9 9}$ & $\mathbf{2 0 0 0}$ \\
Capital & & & & & & \\
ABC & 21,2 & 22,8 & 21,6 & 20,7 & 19,0 & 16,0 \\
Guarulhos & 15,7 & 15,0 & 16,3 & 14,4 & 13,2 & 11,6 \\
Demais municípios da RMSP & 4,8 & 5,1 & 5,1 & 4,6 & 4,6 & 4,3 \\
RA Campinas & 8,5 & 8,8 & 9,1 & 9,7 & 9,9 & 9,3 \\
RA São José dos Campos & 20,8 & 18,8 & 18,6 & 20,1 & 21,0 & 23,6 \\
RA Sorocaba & 8,8 & 9,2 & 9,4 & 9,6 & 10,6 & 13,9 \\
RM Baixada Santista & 5,4 & 5,5 & 5,8 & 5,8 & 5,8 & 5,3 \\
Total SP & 3,2 & 2,2 & 2,2 & 2,3 & 2,5 & 4,2 \\
\hline
\end{tabular}

Fontes: Secretaria da Fazenda do Estado de São Paulo (dados do VAF) e Fundação Seade (1996). Elaboração do autor.

Nesse sentido, os dados empíricos disponíveis, longe de indicar uma terciarização da metrópole, parecem nos conduzir a interpretações alternativas sobre a dinâmica metropolitana, baseadas em uma análise intersetorial das cadeias produtivas e no movimento de industrialização dos serviços.

Meu escopo, doravante, é trazer à baila os padrões locacionais da indústria paulista, no sentido de evidenciar que o setor industrial está no centro das transformações socioeconômicas experimentadas pela metrópole nos últimos anos.

\section{PADRÕES LOCACIONAIS DA INDÚSTRIA PAULISTA (1970-2000): A AMPLIAÇÃO DAS ECONOMIAS DE AGLOMERAÇÃO METROPOLITANAS}

Nesta parte do trabalho, buscarei explicitar empiricamente os padrões locacionais da indústria paulista desde os anos 1970, pico da concentração industrial na RMSP. Demonstrarei, com base nos dados do VTI das indústrias extrativas e de transformação, que os movimentos de expansão industrial no Estado de São Paulo não representam uma interiorização ampla da indústria paulista, tampouco sustentam uma su- 
posta perda de centralidade da indústria da RMSP, não obstante os profundos processos de reestruturação urbano-regional das últimas três décadas, os quais engendram perdas significativas da participação relativa da metrópole paulista na composição do VTI estadual e nacional.

\section{Os Movimentos Regionais da Indústria Paulista com Relação ao VTI Estadual}

Do ponto de vista das participações relativas das 16 microrregiões que compõem a categoria que denomino "metrópole expandida" ${ }^{3}$ no VTI estadual, percebemos um intenso movimento de reorganização da indústria no espaço, uma vez que a indústria localizada na RMSP, que em 1970 perfazia 74,5\% do VTI produzido no Estado de São Paulo, declinou, em 2000, para 42,8\% desse total (ver Tabela 5). Ademais, cabe notar o vertiginoso processo de desconcentração industrial da microrregião São Paulo, formada pelo município de São Paulo e as cidades que compõem o ABC paulista, visto que, entre 1970 e 2000, o declínio desses municípios na composição relativa do VTI estadual foi de 36,3 pontos percentuais - de 67,0\% em 1970 para 30,7\% em 2000 (ver Tabela 5).

Interessante notar que houve crescimento relativo de todas as outras cinco microrregiões que compõem a RMSP, a saber: Guarulhos, Osasco, Mogi das Cruzes, Itapecerica da Serra e Franco da Rocha ${ }^{4}$. Dessa forma, as perspectivas que tomam a desindustrialização da RMSP como um processo inevitável e que corre a passos largos necessitam de uma série de ponderações de ordem empírica. Em primeiro lugar, é relevante apontar que, entre 1970 e 2000, as cinco regiões que estão no entorno da microrregião São Paulo aumentaram a sua participação relativa no VTI do Estado de São Paulo de 7,5\% para 12,1\% (ver Tabela 5) ${ }^{5}$.

Destarte, esses dados evidenciam que o processo de industrialização tem sofrido alterações consideráveis dentro dos próprios limites territoriais da RMSP, de forma que uma parte da expansão da indústria no Estado de São Paulo tem sido absorvida pelos espaços econômicos no entorno do núcleo metropolitano, composto pela capital e o $\mathrm{ABC}-\mathrm{ou}$ seja, a microrregião São Paulo.

O processo de desconcentração da metrópole não é, portanto, homogêneo, mas determinado pelo desmonte parcial do espaço de produção que foi fortalecido nos anos desenvolvimentistas, qual seja, a conjunção da cidade de São Paulo com os municípios do ABC. 
Tabela 5

Evolução da Participação das Microrregiões da "Metrópole Expandida" na Composição do VTI do Estado de São Paulo. Indústrias Extrativas e de

Transformação (1970-2000), em Porcentagem

\begin{tabular}{l|r|r|r|r|r|r}
\hline Microrregiões/Anos & $\mathbf{1 9 7 0}$ & $\mathbf{1 9 7 5}$ & $\mathbf{1 9 8 0}$ & $\mathbf{1 9 8 5}$ & $\mathbf{1 9 9 6}$ & $\mathbf{2 0 0 0}$ \\
\hline 1 - São Paulo & 67,0 & 60,5 & 52,1 & 44,1 & 39,4 & 30,7 \\
2 - Campinas & 4,4 & 8,3 & 8,3 & 9,7 & 9,7 & 13,7 \\
3 - São José dos Campos & 2,6 & 3,6 & 4,8 & 7,2 & 9,1 & 13,0 \\
4 - Sorocaba & 1,8 & 1,9 & 3,0 & 3,3 & 3,8 & 5,1 \\
5 - Guarulhos & 2,6 & 3,7 & 3,7 & 4,6 & 2,4 & 4,4 \\
6 - Santos & 2,7 & 2,3 & 3,5 & 4,3 & 1,8 & 3,3 \\
7 - Osasco & 2,4 & 2,3 & 3,0 & 3,4 & 3,6 & 3,3 \\
8 - Jundiaí & 1,9 & 2,1 & 2,3 & 2,0 & 1,6 & 2,9 \\
9 - Mogi das Cruzes & 1,8 & 1,7 & 2,3 & 2,6 & 2,6 & 2,2 \\
10 - Itapecerica da Serra & 0,5 & 0,8 & 1,4 & 1,6 & 2,2 & 2,2 \\
11 - Piracicaba & 0,8 & 1,3 & 1,5 & 1,3 & 1,2 & 1,3 \\
12 - Limeira & 1,4 & 1,3 & 1,4 & 1,4 & 1,8 & 1,3 \\
13 - Mogi Mirim & 0,8 & 0,8 & 0,9 & 1,0 & 1,0 & 1,3 \\
14 - Bragança Paulista & 0,3 & 0,3 & 0,4 & 0,6 & 0,6 & 0,7 \\
15 - Tatuí & 0,1 & 0,1 & 0,3 & 0,3 & 0,4 & 0,4 \\
16 - Franco da Rocha & \\
Total “Metrópole Expandida” & 0,2 & 0,2 & 0,3 & 0,3 & - & - \\
Total RMSP(2) & 91,3 & 91,2 & 89,2 & 87,7 & 81,4 & 85,8 \\
“Metrópole Expandida” - RMSP & 74,5 & 69,2 & 62,8 & 56,6 & 50,2 & 42,8 \\
Outras Microrregiões SP & 16,8 & 22,0 & 26,4 & 31,1 & 31,2 & 43,0 \\
Estado de São Paulo & 8,7 & 8,8 & 10,8 & 12,3 & 18,6 & 14,2 \\
\hline
\end{tabular}

Fontes: Fundação Instituto Brasileiro de Geografia e Estatística (FIBGE), Censo Industrial 1970; Censo Industrial 1975; Censo Industrial 1980; Censos Econômicos 1985 e Pesquisa Industrial 2000. Servidor de Mapas (www.ibge.gov.br). Elaboração do autor.

(1)Dados de VTI indisponíveis para a microrregião Franco da Rocha para os anos de 1996 e 2000. De acordo com os dados da Pesquisa Industrial 2000, essa não figurou entre as principais microrregiões industriais do Brasil, de modo que sua participação no VTI nacional foi de $0,0 \%$, pouco significando para efeitos de mensuração estatística (IBGE, 2002:37).

(2)A Região Metropolitana de São Paulo (RMSP) é composta por seis microrregiões: São Paulo, Guarulhos, Osasco, Mogi das Cruzes, Itapecerica da Serra e Franco da Rocha.

Não obstante, o crescimento das regiões no entorno da microrregião São Paulo foi muito inferior ao aumento relativo de participação das microrregiões contíguas à RMSP. Assim, por exemplo, a região de Guarulhos, que em 1970 contava com uma produção industrial similar à da região de São José dos Campos (com 2,6\% do VTI do estado para am- 
bas), foi responsável, em 2000, pela terça parte da produção de São José dos Campos. Neste fato se expressa o crescimento industrial acentuado de regiões nas bordas da RMSP (ver Tabela 5).

A análise da Tabela 5 é importante para que possamos perceber que o movimento de desconcentração da indústria paulista tem se restringido, maciçamente, às áreas contíguas à RMSP, evidenciando que o processo não se constitui em uma expressão industrial alternativa à RMSP, mas complementar a ela, conforme as proposições teóricas e empíricas que tenho explorado neste artigo.

Embora em um ritmo menos acelerado do que outras regiões da "metrópole expandida", as microrregiões da RMSP, excetuando-se São Paulo, também aumentaram sua participação na indústria paulista, fato este que derruba o mito de um declínio industrial homogêneo da RMSP, explicado, de maneira simplista, por deseconomias de aglomeração associadas ao gigantismo assumido pela metrópole como expressão das políticas desenvolvimentistas.

Assim, podemos identificar três padrões macrorregionais de reorganização da indústria no território paulista desde os anos 1970. Em primeiro lugar, é possível apontar um padrão relativamente intenso de desconcentração industrial na RMSP, uma vez que a indústria da região participa com menos da metade do VTI do setor industrial comparativamente ao ano de 1970 (ver Tabela 5).

Em segundo lugar, podemos perceber que as regiões que mais cresceram no estado, em termos de sua produção industrial, nas últimas três décadas foram as microrregiões que se situam no entorno da RMSP. Destarte, os setores industriais desse anel externo da RMSP, os quais, em 1970, já detinham uma participação importante na indústria paulista, perfazendo $16,8 \%$ do VTI estadual, passam, em 2000, a responder por $43,0 \%$ do VTI estadual - um crescimento relativo de $155,9 \%$, superando, inclusive, a indústria da RMSP em termos relativos.

Em terceiro lugar, as outras regiões do Estado de São Paulo fora da "metrópole expandida" apresentaram um crescimento relativo considerável, ainda que sua indústria nem de longe se assemelhe ao dinamismo tanto da RMSP quanto do entorno metropolitano: sua participação no VTI estadual, que em 1970 era de 8,7\%, passa a 14,2\% em 2000. Em suma, o movimento de expansão da indústria metropolitana foi absorvido com muito mais força pelas regiões em seu entorno, evidenci- 
ando processos de integração produtiva e economias externas que são metropolitanos por excelência, como apontado anteriormente neste artigo.

A análise dos dados do VTI sob o enfoque metodológico da "metrópole expandida" mostra que praticamente não houve alteração nos padrões de concentração territorial da indústria em uma área bastante restrita do Estado de São Paulo. Se, do ponto de vista da dinâmica interna dessa macrorregião urbano-industrial, puderam ser verificadas intensas mudanças - como a desconcentração industrial na RMSP em favor de seu anel externo -, a perspectiva conjunta dessas regiões evidencia que a categoria "metrópole expandida" sofreu perdas mínimas na sua participação relativa na composição do VTI do Estado de São Paulo.

Em 1970, as indústrias localizadas na "metrópole expandida" - devido ao enorme peso dos encadeamentos industriais da cidade de São Paulo e municípios do $\mathrm{ABC}$ e das políticas desenvolvimentistas que favoreceram as indústrias de bens de capital e consumo duráveis, maciçamente presentes nessa região - respondiam por 91,3\% do VTI do Estado de São Paulo, evidenciando a quase inexistência da indústria em outras regiões do estado. Os dados do VTI disponíveis para o ano de 2000 não deixam margens a dúvidas a respeito do caráter restrito do processo de interiorização da indústria paulista, pois os setores industriais situados na "metrópole expandida" perderam apenas 5,5 pontos percentuais em relação à sua participação relativa em 1970 - passaram de $91,3 \%$ para $85,8 \%$ durante esses anos.

Tendo em vista que todas as microrregiões da "metrópole expandida", excetuando-se São Paulo, crescem ou se mantêm estáveis com relação à sua indústria, cabe observar que foi a perda de dinamismo da indústria da RMSP, impulsionada pelas perdas da capital e do ABC, a principal causa das perdas relativas observadas na "metrópole expandida" entre 1970 e 2000 (ver Tabela 5).

Do ponto de vista da distribuição do VTI no Estado de São Paulo entre os anos de 1970 e 2000, podemos notar que as transformações mais intensas no que concerne ao setor industrial processaram-se no interior da "metrópole expandida", na medida em que as perdas sucessivas da RMSP em termos do VTI foram absorvidas, em grande parte, pelas regiões no seu entorno (ver Gráfico 3). 


\section{Gráfico 3}

Participações Relativas de Sub-Regiões do Estado de São Paulo na Composição do VTI Estadual. Indústrias Extrativas e de Transformação (1970-2000),

em Porcentagem

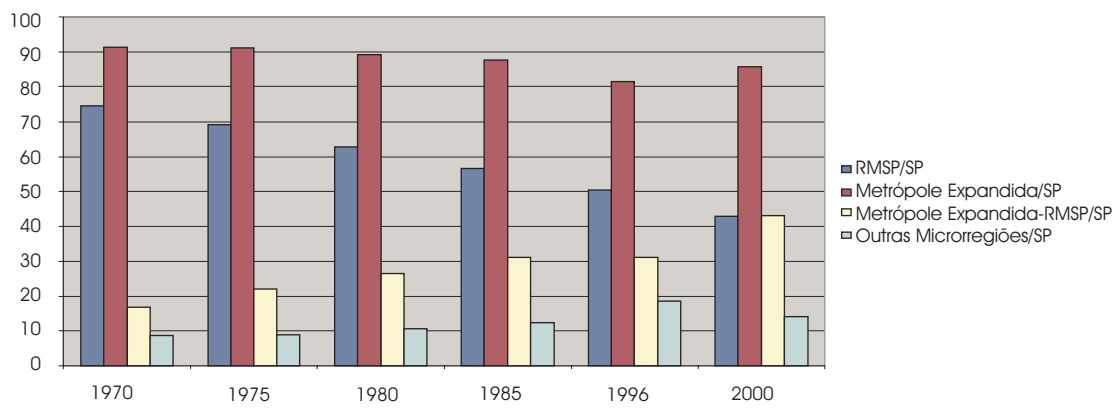

Fontes: Fundação Instituto Brasileiro de Geografia e Estatística (FIBGE), Censo Industrial (1970); Censo Industrial (1975); Censo Industrial (1980); Censos Econômicos (1985); Pesquisa Industrial (2000). Servidor de Mapas (www.ibge.gov.br). Elaboração do autor.

Ademais, o Gráfico 3 mostra que a distância entre os níveis de produção industrial da "metrópole expandida" e de outras regiões do Estado de São Paulo não nos permite asseverar que um processo de interiorização da indústria esteja ocorrendo no estado, visto que os ganhos das regiões externas à "metrópole expandida" são mínimos em relação a 1970.

Dos quatro arranjos regionais considerados no Gráfico 3, as regiões do entorno metropolitano são as únicas que combinaram crescimento acelerado em termos industriais com uma expressiva participação no VTI estadual desde 1970. Destarte, se em 1970 existiam profundas desigualdades no que tange à participação da RMSP e do anel externo metropolitano na produção industrial estadual - os setores da indústria da RMSP contribuíam com $74,5 \%$, e o entorno metropolitano, com 16,8\% do VTI estadual -, em 2000 podemos observar uma situação de equilíbrio entre as indústrias localizadas na RMSP e no entorno da metrópole, pois as primeiras participaram com $42,8 \%$ do VTI estadual, e as últimas, com $43,0 \%$ - de sorte que o entorno metropolitano tende a tornar-se a principal sub-região industrial nacional. Nesse novo arranjo territorial, portanto, a RMSP, tomada isoladamente, deixa de ser a região industrial predominante no Brasil, já que divide esse papel com as regiões em seu entorno, em um forte movimento de integração produtiva. 
Na próxima seção, percorrerei o mesmo caminho de análise empírica dos padrões de expansão da indústria paulista, sob o enfoque da participação relativa das microrregiões do estado no VTI nacional.

\section{Os Movimentos Regionais da Indústria Paulista com Relação ao VTI Nacional}

Em que pese o movimento de desconcentração relativa da indústria paulista, resultado, em boa medida, do deslocamento da matriz setorial de investimentos produtivos estatais nos anos 1970 - que privilegiou setores intensivos em recursos naturais, de modo a favorecer uma certa dispersão territorial da indústria para várias unidades da Federação (Negri, 1996) -, podemos verificar que, excetuando-se a RMSP, houve crescimento relativo da indústria tanto no entorno metropolitano quanto nas regiões exteriores à "metrópole expandida". Desse modo, o gigantismo metropolitano, essência do crescimento econômico desenvolvimentista, bem como os esforços do Estado autoritário para refrear a concentração regional no Brasil produziram efeitos consideráveis de deslocamento industrial da RMSP para outras regiões do país.

No que se refere à participação relativa no VTI nacional, observamos uma profunda reordenação territorial no Estado de São Paulo, uma vez que a microrregião São Paulo, que em 1970 participava com 38,9\% do VTI nacional, passa a contribuir com 13,9\% em 2000. Nesse período, as outras cinco microrregiões que conformam a RMSP mantiveram-se praticamente estáveis em relação ao VTI nacional: em 1970, contribuíam com 4,2\% do VTI nacional, ao passo que em 2000 perfaziam 5,5\%, indicando que, ao contrário do que se possa pensar, o processo de desconcentração industrial não é homogêneo na metrópole, ainda que o Estado de São Paulo tenha perdido produção industrial nessas últimas três décadas (ver Tabela 6).

Não obstante as sucessivas perdas estaduais na composição relativa do VTI nacional, as microrregiões do estado que mais cresceram nacionalmente localizam-se no anel externo metropolitano. Os setores industriais desse conjunto de regiões, que em 1970 já possuíam participação expressiva no VTI nacional (9,6\%), em 2000 dobraram sua participação, perfazendo 19,5\% do VTI nacional e superando a metrópole (ver Tabela 6).

De outro lado, as regiões que se situam fora da "metrópole expandida" avançaram apenas 1,6 ponto percentual na composição do VTI nacio- 
nal entre 1970 e 2000, passando de 4,8\% para 6,4\% nesse período, o que mostra que devemos ponderar o processo de interiorização da indústria no Estado de São Paulo, apesar da importância da indústria localizada nessas regiões (ver Tabela 6).

\section{Tabela 6}

Evolução da Participação das Microrregiões da "Metrópole Expandida" na Composição do VTI do Brasil. Indústrias Extrativas e de Transformação (1970-2000), em Porcentagem

\begin{tabular}{l|r|r|r|r|r|c}
\hline Microrregiões/Anos & $\mathbf{1 9 7 0}$ & $\mathbf{1 9 7 5}$ & $\mathbf{1 9 8 0}$ & $\mathbf{1 9 8 5}$ & $\mathbf{1 9 9 6}$ & $\mathbf{2 0 0 0}$ \\
\hline 1 - São Paulo & 38,0 & 33,1 & 27,3 & 20,9 & 19,5 & 13,9 \\
2 - Campinas & 2,5 & 4,6 & 4,4 & 4,6 & 4,8 & 6,2 \\
3 - São José dos Campos & 1,5 & 2,0 & 2,5 & 3,4 & 4,5 & 5,9 \\
4 - Sorocaba & 1,0 & 1,0 & 1,6 & 1,6 & 1,9 & 2,3 \\
5 - Guarulhos & 1,5 & 2,0 & 1,9 & 2,2 & 1,2 & 2,0 \\
6 - Santos & 1,5 & 1,3 & 1,9 & 2,0 & 0,9 & 1,5 \\
7 - Osasco & 1,4 & 1,3 & 1,6 & 1,6 & 1,8 & 1,5 \\
8 - Jundiaí & 1,1 & 1,2 & 1,2 & 0,9 & 0,8 & 1,3 \\
9 - Mogi das Cruzes & 1,0 & 0,9 & 1,2 & 1,2 & 1,3 & 1,0 \\
10 - Itapecerica da Serra & 0,2 & 0,4 & 0,8 & 0,8 & 1,1 & 1,0 \\
11 - Piracicaba & 0,5 & 0,7 & 0,8 & 0,6 & 0,6 & 0,6 \\
12 - Limeira & 0,8 & 0,7 & 0,7 & 0,7 & 0,9 & 0,6 \\
13 - Mogi Mirim & 0,5 & 0,4 & 0,5 & 0,5 & 0,5 & 0,6 \\
14 - Bragança Paulista & 0,1 & 0,1 & 0,2 & 0,3 & 0,3 & 0,3 \\
15 - Tatuí & 0,0 & 0,1 & 0,1 & 0,1 & 0,2 & 0,2 \\
16 - Franco da Rocha (1) & 0,1 & 0,1 & 0,2 & 0,1 & $(\mathrm{X})$ & $(\mathrm{X})$ \\
Total “Metrópole Expandida” & 51,8 & 49,9 & 46,9 & 41,5 & 40,3 & 38,9 \\
Total RMSP(2) & 42,2 & 37,8 & 33,0 & 26,8 & 24,9 & 19,4 \\
“Metrópole Expandida” - RMSP & 9,6 & 12,1 & 13,9 & 14,7 & 15,4 & 19,5 \\
Outras Microrregiões SP & 4,8 & 4,8 & 5,5 & 5,9 & 9,2 & 6,4 \\
Total Estado de São Paulo & 56,6 & 54,7 & 52,4 & 47,4 & 49,5 & 45,3 \\
Total Brasil & $\mathbf{1 0 0 , 0}$ & $\mathbf{1 0 0 , 0}$ & $\mathbf{1 0 0 , 0}$ & $\mathbf{1 0 0 , 0}$ & $\mathbf{1 0 0 , 0}$ & $\mathbf{1 0 0 , 0}$ \\
\hline
\end{tabular}

Fontes: Fundação Instituto Brasileiro de Geografia e Estatística (FIBGE), Censo Industrial (1970); Censo Industrial (1975); Censo Industrial (1980); Censos Econômicos (1985); Pesquisa Industrial (2000). Servidor de Mapas (www.ibge.gov.br). Elaboração do autor.

(1) Dados do VTI indisponíveis para a microrregião Franco da Rocha para os anos de 1996 e 2000. De acordo com os dados da Pesquisa Industrial 2000, esta microrregião não figurou entre as principais microrregiões industriais do Brasil, de modo que sua participação no VTI nacional foi de 0,0\%, pouco significando para efeitos de mensuração estatística (IBGE, 2002:37).

(2) A Região Metropolitana de São Paulo (RMSP) é composta por seis microrregiões: São Paulo, Guarulhos, Osasco, Mogi das Cruzes, Itapecerica da Serra e Franco da Rocha. 
Quando analisada em conjunto, a "metrópole expandida" também apresenta perdas relativas consideráveis no que concerne ao VTI nacional, principalmente devido à queda da RMSP, o que indica que o epicentro da desconcentração regional da indústria paulista foi exatamente a área metropolitana que emergiu do desenvolvimentismo. A despeito de suas perdas relativas, a distância entre a "metrópole expandida" e outras regiões industriais brasileiras evidencia que os seus encadeamentos industriais continuam a ter papel central nos rumos da industrialização brasileira, principalmente do ponto de vista dos setores industriais intensivos em tecnologia e conhecimento.

Como resultado da intensidade da dispersão territorial da indústria da RMSP para outras regiões do estado e do país, a "metrópole expandida" apresentou um ritmo de desconcentração industrial um pouco superior à média do Estado de São Paulo.

No entanto, a desagregação dos movimentos de desconcentração do VTI da indústria por microrregiões do estado em relação ao VTI nacional mostra que houve intensos processos de concentração industrial tanto no anel externo à RMSP quanto nas áreas mais distantes do estado (ver Tabela 6). No que tange aos processos de crescimento regional no Estado de São Paulo, devemos notar que todos os arranjos regionais analisados apresentaram acentuado crescimento relativo do VTI do es-

\section{Gráfico 4}

Participações Relativas de Sub-Regiões do Estado de São Paulo na Composição do VTI Nacional. Indústrias Extrativas e de Transformação (1970-2000), em Porcentagem

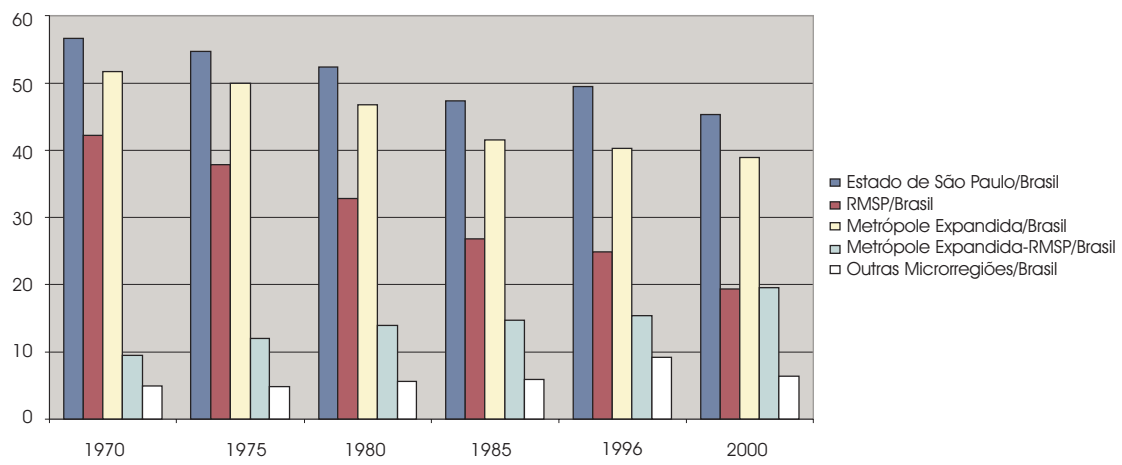

Fontes: Fundação Instituto Brasileiro de Geografia e Estatística (FIBGE), Censo Industrial (1970); Censo Industrial (1975); Censo Industrial (1980); Censos Econômicos (1985); Pesquisa Industrial (2000). Servidor de Mapas (www.ibge.gov.br). Elaboração do autor. 
tado em relação ao VTI nacional, não obstante esse crescimento seja muito mais intenso em regiões contíguas à RMSP (ver Tabela 6).

A importância do entorno da metrópole no que diz respeito aos setores industriais que abriga pode ser verificada no Gráfico 4, o qual mostra que as regiões do Estado de São Paulo que mais ganharam participação no VTI nacional são aquelas conformadas por 10 microrregiões no anel externo metropolitano. $\mathrm{O}$ dinamismo industrial dessa região pode ser destacado no contraste com os outros arranjos territoriais analisados no Gráfico 4, uma vez que este apresenta quedas relativas do Estado de São Paulo e da RMSP e um pequeno aumento da participação relativa das microrregiões no exterior da "metrópole expandida".

Assim, claro está que uma separação territorial entre RMSP e o restante do estado para caracterizar os processos de desenvolvimento industrial no Estado de São Paulo é teoricamente inconsistente e metodologicamente inadequada para que captemos os padrões setoriais diferenciados da indústria paulista, por um lado, e as territorialidades engendradas pelos diferentes setores industriais, por outro. Uma nova agenda de estudos, baseada nas diferentes regiões do estado, deve buscar o entendimento dos mecanismos de aglomeração que agem distintamente em termos setoriais e regionais no Estado de São Paulo. A participação das diferentes regiões de São Paulo na composição do VTI nacional indica a necessidade da construção de um novo arcabouço de pesquisa para que possamos nos aprofundar nas potencialidades e fraquezas de várias sub-regiões industriais. Somente assim o poder público poderá intervir positivamente no sentido de impulsionar os encadeamentos industriais presentes no estado, superando a noção do senso comum de que a metrópole paulista não tem mais na indústria seu centro nervoso.

\section{CONCLUSÕES}

Neste artigo, procurei trazer à baila um debate teórico e metodológico que se verifica entre as principais correntes de pesquisa que tratam das tendências produtivas da RMSP. Meu objetivo, nesta conclusão, é não somente sistematizar esse debate no que concerne aos seus pontos principais, mas também apontar algumas questões que se mantêm para as futuras pesquisas que vierem a ser desenvolvidas sobre os processos de transformação socioeconômica na metrópole paulista. 
Em um primeiro conjunto de hipóteses que foram tratadas neste texto podemos situar a tradição de pesquisa que compreende a literatura das cidades globais ou mundiais, tendo como escopo oferecer, ainda que parcialmente, uma agenda alternativa de estudo dos problemas metropolitanos.

Entendendo as metrópoles como espaços de produção pós-industrial, a literatura sobre as cidades globais e cidades mundiais observa uma tendência de crescimento vertiginoso do setor de serviços, na esteira da intensificação do papel do capital financeiro e do terciário intensivo em conhecimento como elementos dinâmicos basilares dessa nova economia. Assim, as cidades globais ou mundiais centralizariam os grandes conglomerados do setor financeiro e de prestação de serviços avançados, que se tornam extremamente dependentes da infra-estrutura, da mão-de-obra altamente especializada e da disponibilidade de informações presentes nos grandes centros urbanos. Nesse sentido, o setor de serviços tenderia a superar a indústria em termos de geração de dinamismo econômico e social nos principais conglomerados urbanos (Beaverstock et alii, 1999; Taylor et alii, 2002; Sassen, 2001). Tendo essa literatura alternativa como referência, busquei testar suas hipóteses empiricamente, bem como avançar na direção de novas abordagens teórico-metodológicas sobre a metrópole paulista.

Pude, destarte, perceber que a dinâmica socioeconômica da metrópole paulista está longe de apresentar os mesmos padrões verificados nas chamadas cidades globais ou cidades mundiais de primeira ordem. Por um lado, os dados da produção e investimentos do setor industrial evidenciam que a indústria se insere como elemento motor principal do desenvolvimento no território. Por outro lado, o setor financeiro e o terciário intensivo em inovação localizam-se, primordialmente, na metrópole paulista - com supremacia da cidade de São Paulo, que se fortalece cada vez mais como o principal centro financeiro e de serviços da América Latina, juntamente com a cidade do México (Beaverstock et alii, 1999; Parnreiter, 2002).

Os resultados empíricos obtidos nesta pesquisa nos encaminham para uma outra perspectiva acerca do desenvolvimento socioeconômico da RMSP. Devemos considerar que a dinâmica mais recente da acumulação capitalista, estribada em um grau mais acentuado de internacionalização e integração das atividades econômicas, não foi capaz de engendrar circuitos de acumulação de capital que deslocassem a indús- 
tria para um papel secundário. As imagens da sociedade pós-industrial que estariam dominando a paisagem urbana atual mancham-se no primeiro contato com as evidências empíricas, como procurei demonstrar ao longo deste artigo.

Os fluxos de investimentos diretos estrangeiros, a desregulamentação do setor financeiro nacional, a frenética busca de ganhos no curto prazo nas principais bolsas de valores do mundo subdesenvolvido e a expansão do escopo das empresas transnacionais revelaram-se componentes causais ineficazes em assegurar que um novo espaço urbano, impulsionado pelo setor financeiro e pelo terciário intensivo em informação e conhecimento, surgiria nesse novo arranjo econômico.

Desse modo, em um contexto de inadequação dos modelos teóricos e empíricos dominantes para explicar a dinâmica socioeconômica da RMSP, devemos buscar construir um tipo de pesquisa urbano-regional voltada para os contextos nacionais e regionais específicos (Markusen, 1999a). O foco de análise é assim deslocado de visões generalizantes acerca dos impactos da globalização para as trajetórias particulares dos Estados nacionais e das unidades subnacionais no que tange à produção do espaço, de modo a apreender como a ação do Estado - principalmente por meio de suas políticas de desenvolvimento-, a dinâmica da acumulação capitalista na região e os contextos sociais tornam-se, no caso da RMSP, elementos de análise que precedem a globalização e sua suposta primazia causal na explicação das realidades contemporâneas da metrópole paulista.

Não obstante apoiar-se em elementos ontológicos distintos da literatura sobre as cidades globais, uma segunda linha de pesquisa que procurei abordar neste artigo refere-se às teses da reversão da polarização em São Paulo, que seria levada a cabo por um processo de interiorização da indústria no estado. Não se trata, aqui, de substituição estrutural da indústria como motor do desenvolvimento, mas de sucessão regional da indústria como expressão das novas formas de organização da produção no estado. Assim, o espaço metropolitano deixaria de ter precedência sobre os arranjos produtivos.

Obviamente, não estou negando o movimento de desconcentração industrial verificado na RMSP a partir dos anos 1980 (Cano, 1998). A tibieza desse movimento, entretanto, tem reforçado um espaço de aglomeração radial cingindo a metrópole, conferindo à RMSP extrema importância em termos industriais, traduzida por sua elevada participação 
no VTI nacional. Assim, cabe notar que os movimentos da desconcentração industrial se limitam a espaços de produção dependentes da RMSP, como Campinas, São José dos Campos, Santos e Sorocaba, evidenciando o papel da RMSP como centro irradiador do desenvolvimento brasileiro (Diniz, 1994). Esse macroespaço urbano praticamente mantém inalteradas suas altas participações no VTI brasileiro, tornando infundadas as hipóteses sobre movimentos intensos de desindustrialização no Estado de São Paulo e na metrópole paulista.

Busquei, em resumo, demonstrar que a metrópole ainda se coloca como o centro irradiador do desenvolvimento industrial estadual e nacional, uma vez que a análise dos dados de produção industrial não nos revela a formação, no Estado de São Paulo, de significativos espaços produtivos afastados do peso da malha produtiva metropolitana. Assim, uma parcela substancial do VTI brasileiro é produzida em uma macroaglomeração urbano-industrial que não ultrapassa um raio de aproximadamente $150 \mathrm{~km}$ da capital paulista (Azzoni, 1986; Storper, 1991; Matteo e Tapia, 2002). Ademais, cabe observar que os dados do produto industrial paulista mantêm praticamente os mesmos níveis de produção do VTI verificados em meados da década de 1980 (IBGE, 2002: 23). Sob esse aspecto, analisamos as configurações produtivas recentes da RMSP, demonstrando o extremo dinamismo da indústria no território e a formação de um macroespaço de produção urbano-industrial como resultado da expansão da malha produtiva metropolitana.

A meu ver, o peso dos encadeamentos produtivos da RMSP na estrutura industrial do estado e do país tem sido subestimado por estratégias de investigação inadequadas do ponto de vista da regionalização do Estado de São Paulo. Ao regionalizar o estado em duas grandes categorias socioeconômicas, a saber, "metrópole" e "interior", os trabalhos que se baseiam na proposição da interiorização da indústria tornam-se empiricamente inadequados por não deixarem perceber que os processos de expansão da indústria paulista são muito diferenciados em termos regionais, com o predomínio das microrregiões e regiões administrativas do entorno metropolitano. A grande categoria "interior" apenas confunde a análise e subestima o papel da RMSP na geração de economias de aglomeração industriais e intersetoriais. Como vimos aqui, análises empiricamente mais detalhadas por microrregiões ou regiões de governo em São Paulo mostraram, em grande medida, um movimento de dispersão integrada da indústria paulista. Portanto, busquei relativizar, por exemplo, afirmações como as de Caiado (2002:175), que 
diz que "o interior paulista se consolidou como a segunda região mais industrializada do Brasil e, se consideradas as trajetórias de redução da participação da RMSP e expansão do interior, pode-se inferir que em poucos anos o interior de São Paulo será a área de maior concentração industrial brasileira".

Os autores que tratam dos movimentos regionais da indústria em São Paulo não explicam as profundas desigualdades existentes na área que compreende todas as regiões do estado excetuando-se a RMSP - o chamado "interior paulista" (Negri e Pacheco, 1994; Negri, 1996; Tavares, 2000; Caiado, 2002). Espero ter demonstrado empiricamente, no decorrer deste artigo, que o caráter da industrialização é muito distinto entre essas regiões e que há um evidente predomínio da RMSP e seu entorno imediato em quase todos os segmentos da indústria, num padrão territorial similar ao que vem tomando forma na cidade do México, outra importante megacidade da América Latina (Aguilar, 1999; 2002; Aguilar e Ward, 2003). Além disso, o trabalho buscou questionar a tese de que existe, de fato, uma interiorização da indústria em São Paulo, com base na evidência de que $39 \%$ do VTI nacional são produzidos em uma área de 14\% do território paulista (IBGE, 2002:23), indicando uma penetração limitada da indústria em áreas mais afastadas da metrópole desde os anos 1970.

Embora tenha ocorrido, de fato, um processo de interiorização da indústria em determinados segmentos da cadeia produtiva - como, por exemplo, os setores de produtos alimentícios e bebidas, madeira e fabricação de produtos relacionados ao couro -, isso é muito pouco para afirmar que estamos diante de um processo de interiorização do desenvolvimento industrial em São Paulo, principalmente se levarmos em conta o fato de que os segmentos mais complexos das cadeias produtivas continuam apresentando padrões metropolitano-dependentes de localização.

Em uma terceira vertente de análise, visei tratar da indústria e dos serviços como setores economicamente integrados na metrópole, o que não tem sido percebido por grande parte da literatura que trata das mudanças produtivas metropolitanas.

Entendo, assim, que a "ilusão estatística" de que o setor de serviços tenderia a dominar a paisagem socioeconômica metropolitana - para a qual somos freqüentemente conduzidos - tem suas raízes em uma compreensão inadequada das relações que movem o setor industrial e 
o setor de serviços, as quais são caracterizadas, essencialmente, por novos padrões de organização da indústria, que vem atravessando processos intensos de reestruturação produtiva nos últimos anos. Assim, muitas atividades que durante o auge da produção em massa eram executadas no interior da empresa industrial foram externalizadas e atualmente são registradas como atividades do terciário, ainda que mantendo uma relação de simbiose com os processos de produção industrial. Dessa forma, o crescimento do setor terciário traz a lume a sua complementaridade com o setor industrial na organização socioeconômica do território, tornando a RMSP não um espaço metropolitano pós-industrial ou terciário, mas uma metrópole industrial de serviços, na medida em que não se trata de uma ruptura entre indústria e serviços, mas de arranjos produtivos baseados na complementaridade entre esses dois setores da vida econômica.

A relativa perda de dinamismo da indústria metropolitana, revelada pelo decréscimo da participação desse setor na composição do VAF metropolitano e estadual, pode ser explicada, em considerável medida, pelas escolhas e pelos processos que dominaram a agenda de governo nos anos 1990, claramente orientada para a abertura comercialque se revelou traumática para a indústria da RMSP, em comparação com outras regiões. Em outros termos, vimos que as renitentes trajetórias de queda da renda e dos níveis de emprego no espaço da metrópole se mostraram extremamente nocivas para setores industriais sensíveis à queda da renda como, por exemplo, os setores de bens de capital e consumo duráveis. Em resumo, é possível afirmar que a perda de fôlego da indústria da RMSP está menos ligada a um processo de transição setorial para os serviços modernos - como nos quer fazer crer a tradição de pesquisa das cidades mundiais - do que a variáveis macroeconômicas como, por exemplo, as taxas de câmbio e os níveis de crescimento do PIB nas últimas décadas.

Em uma visão distinta, noto que as novas economias de aglomeração estribadas em interações indústria-serviços deverão, nos próximos anos, reforçar o caráter industrial da RMSP, principalmente em setores dependentes de serviços modernos como insumos produtivos, na medida em que essas interações são baseadas, primordialmente, na proximidade geográfica entre os agentes econômicos (Miles e Boden, 2000; Storper, 2000). Certamente, o entendimento desses encadeamentos entre os setores industriais e de serviços para a produção de bens intensivos em conhecimento é um dos principais desafios colocados aos pes- 
quisadores que se debruçam sobre as trajetórias socioeconômicas recentes da metrópole paulista. $\mathrm{O}$ foco exclusivo nos arranjos industriais não é mais suficiente, a meu ver, para dar conta das relações sociais complexas que se desenvolvem nos mundos da produção. Como corolário, as políticas de desenvolvimento industrial que não capturem essas redes de conhecimento mútuas e intersetoriais provavelmente elevarão os custos de aprendizado na implementação de medidas que visem ao apoio à produção.

(Recebido para publicação em agosto de 2004) (Versão definitiva em maio de 2005)

\section{NOTAS}

1. Os movimentos defensivos de reestruturação produtiva estão fortemente baseados no aumento de produtividade derivado da terceirização das funções produtivas. Nesse sentido, a elevação dos níveis de produtividade não é extraída primordialmente de movimentos inovadores na produção, mas de processos mais intensivos de exploração da mão-de-obra, estribados na ruptura das antigas alianças entre capital e trabalho (Lipietz, 1986).

2. Claro está, portanto, que, no que diz respeito às recentes configurações produtivas assumidas pela RMSP, há um forte movimento de integração organizacional e espacial entre indústria e serviços, como temos observado neste artigo. Não se trata, destarte, da formação de um espaço metropolitano como expressão de uma "economia de serviços" - que dispensaria a proximidade espacial entre secundário e terciário por conta dos elevados custos de aglomeração na metrópole e do avanço nas tecnologias de comunicação (cf. Sassen, 2001). A “economia de serviços” na RMSP conforma uma contradição em termos, uma vez que tal economia não existe sem seus complexos encadeamentos espaciais e organizacionais com o setor industrial. O legado dos anos 1990 para a RMSP, na abordagem que proponho, é a economia industrial de serviços nos termos de Veltz (2002).

3. Para a análise do VTI, o termo "metrópole expandida" refere-se à RMSP (formada pelas microrregiões de São Paulo, Guarulhos, Osasco, Mogi das Cruzes, Itapecerica da Serra e Franco da Rocha), além de 10 microrregiões no seu entorno, a saber: Bragança Paulista, Campinas, São José dos Campos, Sorocaba, Santos, Jundiaí, Piracicaba, Limeira, Mogi Mirim e Tatuí. Ainda que com um enfoque regional levemente distinto da análise do VAF, por conta do desenho amostral dos dados disponíveis, a tese da expansão integrada da indústria metropolitana não é de modo algum prejudicada, já que os arranjos espaciais utilizados no VAF e no VTI abarcam os principais territórios industriais da "metrópole expandida". 
4. Para a microrregião Franco da Rocha, só possuo dados dos anos entre 1970 e 1985, embora os dados do VAF da Secretaria da Fazenda do Estado de São Paulo sugiram que a participação da região na indústria paulista permaneça inalterada desde 1985.

5. Para chegar a esses números, somei o VTI das microrregiões Guarulhos, Osasco, Mogi das Cruzes, Itapecerica da Serra e Franco da Rocha nos anos de 1970 e 2000, de modo a notar que houve expansão da indústria no anel regional formado pela RMSP, excetuando-se a capital paulista e o ABC.

\section{REFERÊNCIAS BIBLIOGRÁFICAS}

ACCA, Rogério dos Santos. (2003), “Reestruturação Urbano-Regional em São Paulo: Falácias e Fantasias do Apocalipse Industrial Metropolitano". Revista Plural, no 10, pp. 7-48.

AGUILAR, Adrian Guillermo. (1999), “Mexico City Growth and Regional Dispersion: The Expansion of Largest Cities and New Spatial Forms". Habitat International, vol. 23, no 3, pp. 391-412.

. (2002), “Las Mega-Ciudades y las Periferias Expandidas. Ampliando el Concepto en Ciudad de México". Revista EURE, vol. 28, no 85, pp. 121-149.

e WARD, Peter M. (2003), “Globalization, Regional Development, and Mega-City Expansion in Latin America: Analyzing Mexico City's Peri-Urban Hinterland". Cities, vol. 20, no 1, pp. 3-21.

AZZONI, Carlos Roberto. (1986), Indústria e Reversão da Polarização no Brasil. São Paulo, Instituto de Pesquisas Econômicas da Universidade de São Paulo.

BEAVERSTOCK, J. V., SMITH, R. G. e TAYLOR, P. J. (1999), “A Roster of World Cities”. Cities, vol.16, nํㅡ 6, pp. 445-458.

BESSA, Vagner de Carvalho. (2003), O Setor de Serviços às Empresas. São Paulo, Cebrap/Ce. Manuscrito.

CAIADO, Aurílio. (2002), Desconcentração Industrial Regional no Brasil (1985-1998): Pausa ou Retrocesso? Tese de Doutorado, Instituto de Economia, Unicamp, Campinas.

CANO, Wilson. (1998), Desequilibrios Regionais e Concentração Industrial no Brasil. Campinas, Editora da Unicamp.

CARNEIRO, Ricardo. (2002), Desenvolvimento em Crise: A Economia Brasileira no Último Quarto do Século XX. São Paulo, Editora Unesp.

CHANG, Ha-Joon. (1996), The Political Economy of Industrial Policy. London, Macmillan.

COHEN, R. B. (1981), “The New International Division of Labor, Multinational Corporations and Urban Hierarchy", in M. Dear e A. Scott (eds.), Urbanization and Urban Planning in Capitalist Society. New York, Methuen, pp. 287-318. 
COMIN, Álvaro e AMITRANO, Cláudio. (2003), “Economia e Emprego: A Trajetória Recente da RMSP". Novos Estudos CEBRAP, no 66, pp. 53-76.

DINIZ, Clélio Campolina. (1994), “Polygonized Development in Brazil: Neither Decentralization nor Continued Polarization". International Journal of Urban and Regional Research, vol. 18, nํ2, pp. 293-314.

FEAGIN, Joe R. e SMITH, Michael Peter. (1987), “Cities and the International Division of Labor: An Overview", in J. R. Feagin e M. P. Smith (eds.), The Capitalist City: Global Restructuring and Community Politics. Oxford, Blackwell Publishers, pp. 3-36.

FRIEDMANN, John e WOLFF, Goetz. (1982), “World City Formation: An Agenda for Research and Action". International Journal of Urban and Regional Research, vol. 6, no 3, pp. 309-344.

FUNDAÇÃO SEADE. (1996), Pesquisa da Atividade Econômica Paulista. São Paulo, Fundação Seade.

HAY, Donald A. (1997), The Post 1990 Brazilian Trade Liberalization and the Performance of Large Manufacturing Firms: Productivity, Market Share and Productivity. Rio de Janeiro, Ipea.

IBGE - INSTITUTO BRASILEIRO DE GEOGRAFIA E ESTATÍ́STICA. (2002), Pesquisa Industrial 2000. Brasília, IBGE.

LENCIONI, Sandra. (2003a), “Uma Nova Determinação do Urbano: O Desenvolvimento do Processo de Metropolização do Espaço”, in A. F. A. Carlos e A. I. G. Ramos (orgs.), Dilemas Urbanos: Novas Abordagens sobre a Cidade. São Paulo, Contexto.

(2003b), “A Emergência de um Novo Fato Urbano de Caráter Metropolitano em São Paulo. A Particularidade de seu Conteúdo Sócio-Espacial, Seus Limites Regionais e Sua Interpretação Teórica". Anais do X Encontro Nacional da ANPUR, pp. 1-13.

LIPIETZ, Alain. (1986), "New Tendencies in the International Division of Labor: Regimes of Accumulation and Modes of Regulation", in A. Scott e M. Storper (eds.), Production, Work, Territory: The Geographical Anatomy of Industrial Capitalism. Boston, Unwin Hyman, pp. 16-40.

MARKUSEN, Ann R. (1999a), “National Contexts and the Emergence of Second Tier Cities", in A. R. Markusen; Y-S. Lee e S. Digiovanna (eds.), Second Tier Cities: Rapid Growth beyond the Metropolis. Minneapolis, University of Minnesota Press, pp. 65-94.

. (1999b), “Fuzzy Concepts, Scanty Evidence, Policy Distance: The Case for Rigour and Policy Relevance in Critical Regional Studies". Regional Studies, vol. 33, no 9, pp. 869-884.

MARQUES, Eduardo e TORRES, Haroldo. (2000), "São Paulo no Contexto do Sistema Mundial de Cidades". Novos Estudos CEBRAP, no 56, pp. 139-168.

MATTEO, Miguel e TAPIA, Jorge Ruben Biton. (2002), “Características da Indústria Paulista nos Anos 90: Em Direção a uma City-Region?". Revista de Sociologia e Política, ${ }^{\circ}$ 18 , pp. 73-93.

MILES, Ian e BODEN, Mark. (2000), “Are Services Special?”, in M. Boden e I. Miles (eds.), Services and the Knowledge-Based Economy. New York, Continuum. 
MOULAERT, Frank, SCOTT, Allen J. e FARCY, Hélène. (1997), “Producer Services and the Formation of Urban Space", in F. Moulaert e A. J. Scott (eds.), Cities, Enterprises and Society on the Eve of the $21^{\text {st }}$ Century. London, Pinter, pp. 97-112.

NEGRI, Barjas. (1996), Concentração e Desconcentração Industrial em São Paulo (1880-1990). Campinas, Editora da Unicamp.

e PACHECO, Carlos Américo. (1994), “Mudança Tecnológica e Desenvolvimento Regional nos Anos 90: A Nova Dimensão Espacial da Indústria Paulista". Espaço e Debates, $\mathrm{n}^{\mathrm{o}} 38$, pp. 62-82.

PACHECO, Carlos Américo. (1999), “Novos Padrões de Localização Industrial? Tendências Recentes dos Indicadores da Produção e do Investimento Industrial". Texto para Discussão, n 633, Brasília, Ipea, pp. 1-38.

PARNREITER, Christof. (2002), "Mexico: The Making of a Global City", in S. Sassen (ed.), Global Networks, Linked Cities. New York, Routledge, pp. 145-182.

POLLARD, Jane e STORPER, Michael. (1996), “A Tale of Twelve Cities: Change in Dynamic Industries in the 1980s". Economic Geography, vol. 72, no 1, pp. 1-22.

SASSEN, Saskia. (1998), As Cidades na Economia Mundial. São Paulo, Nobel. . (2001), The Global City: New York, London, Tokyo. Princeton, Princeton University Press.

STORPER, Michael. (1991), Industrialization, Economic Development and the Regional Question in the Third World. London, Pion.

. (2000), "Globalization, Localization, and Trade", in G. L. Clark, M. P. Feldman e M. S. Gertler (eds.), The Oxford Handbook of Economic Geography. New York, Oxford University Press, pp. 146-165.

TAVARES, Hermes Magalhães. (2000), “Reestruturação Econômica e as Novas Funções dos Espaços Metropolitanos", in A. C. T. Ribeiro (org.), Repensando a Experiência Urbana da América Latina: Questões, Conceitos e Valores. Buenos Aires, Clacso.

TAYLOR, P. J., CATALANO, G. e GANE, N. (2002), “Geography of Global Change: Cities and Services, 2000-01". GaWC Research Bulletin, ${ }^{\circ} 77$.

TOMLINSON, Mark. (2001), "A New Role for Business Services in Economic Growth", in D. Archibugi e B.-A. Lundvall (eds.), The Globalizing Learning Economy. New York, Oxford University Press, pp. 97-107.

UNITED NATIONS CONFERENCE ON TRADE AND DEVELOPMENT - UNCTAD. (2002a), World Development Report 2002: Transnational Corporations and Export Competitiveness. Genebra, Unctad.

(2002b), UNCTAD Handbook of Statistics. Genebra, Unctad.

VELTZ, Pierre. (1997), “Dynamics of Production Systems, Territories, Cities”, in F. Moulaert e A. J. Scott (eds.), Cities, Enterprises and Society on the Eve of the $21^{\text {st }}$ Century. London, Pinter, pp. 77-96.

(2002), Des Lieux et des Liens. Paris, Editions de L'Aube. 


\begin{abstract}
Recent Industrial Dynamics in Greater Metropolitan São Paulo: From Post-Industrial Perspectives to Consolidation of the Services Industry

The central scope of this article is to prove, in theoretical and empirical terms, that industry is still at the center of the socioeconomic changes experienced by Greater Metropolitan São Paulo (GMSP) and the surrounding territory in recent years. We will thus highlight evidence that the industrial sectors of GMSP provide the basis for the trends toward territorial reorganization of production in the State of São Paulo. Our objective is to demonstrate that notions of a purported post-industrial metropolis and the shift of industrial development to the interior of the State seriously hinder an adequate understanding of the role potentially played by Metropolitan industrial chains in positive development agendas.
\end{abstract}

Key words: regional development; industrialization; metropolitan restructuring

\title{
RÉSUMÉ
}

La Stratégie Productive Récente de la Ville de São Paulo: Des Perspectives Post-Industrielles à la Consolidation de l'Espace Industriel des Services

Dans cet article, on cherche à montrer du point de vue à la fois théorique et empirique que l'industrie reste le point central des changements socioéconomiques subis par la région métropolitaine de São Paulo (RMSP) et ses environs dans les dernières années; pour cela, on signale les éléments prouvant que les secteurs industriels de cette ville sont à l'origine des mouvements de réaménagement territorial de la production de l'État de São Paulo. On essaie de montrer que l'optique de la métropole post-industrielle et de la progression du développement industriel vers les autres villes de l'État peut nuire à une bonne compréhension du rôle que sont censés jouer les engrenages industriels de la ville sur des programmes de développement.

Mots-clé: développement régional; industrialisation; restructuration de la ville 